\title{
Prediction and analysis of long-term variability of temperature and salinity in the Irish Sea
}

\author{
E. F. Young ${ }^{1,2}$ and J. T. Holt ${ }^{1}$
}

Received 16 November 2005; revised 14 July 2006; accepted 27 July 2006; published 25 January 2007.

[1] The variability of temperature and salinity in the Irish Sea over the 40 year period 1960-1999 is investigated using a free-running fine-resolution local area model. The skill of the model to represent observed temperature and salinity variability is assessed using conductivity-temperature-depth survey data (3397 profiles) and a long time series of measurements from Cypris station (southwest of Isle of Man). This clearly

demonstrates that the model can reproduce the observed seasonal and longer-term cycles in temperature, with mean and RMS errors of $-0.01^{\circ} \mathrm{C}$ and $0.78^{\circ} \mathrm{C}$. Particularly apparent is the long-term warming trend at Cypris station and throughout the model domain. Model estimates of salinity are less accurate and are generally too saline (mean and RMS errors are 0.79 and 0.98 practical salinity units). Inaccuracies are likely to arise from boundary conditions and forcing (riverine and surface). However, while absolute values are not particularly well represented, the model reproduces many of the trends in the salinity variability observed at Cypris station, suggesting that the dominant physical processes in the Irish Sea, with timescales up to $\sim 3$ years, are well represented. The model is also used to investigate the variability in temperature stratification. While stratification is confined to approximately the same geographical area in each year of the simulation, there is significant variability in the timing of the onset and breakdown of stratification and in the peak surface to bed temperature difference. Together, these results suggest that a local area model with limited boundary conditions may be sufficiently accurate for climatic investigation of some (locally forced) parameters.

Citation: Young, E. F., and J. T. Holt (2007), Prediction and analysis of long-term variability of temperature and salinity in the Irish Sea, J. Geophys. Res., 112, C01008, doi:10.1029/2005JC003386.

\section{Introduction}

[2] The Irish Sea is a semienclosed sea bounded by England, Wales and southern Scotland to the east and Ireland to the west (Figure 1). It is heavily utilized and supports commercially important fisheries and a thriving leisure industry. It receives freshwater from a $43,000 \mathrm{~km}^{2}$ catchment area [Bowden, 1980], which includes several large industrial centers. In addition to chemical waste there has been concern that high concentrations of nutrients in river and effluent waters could have a major impact on local ecosystems [Gowen et al., 2000]. The discharge of lowlevel nuclear waste from the British Nuclear Fuels Limited reprocessing plant at Sellafield is also of continuing concern [Copplestone et al., 2004]. As a result of these activities, the Irish Sea is a region of great interest and has been extensively studied over the years and a broad picture of the dominant hydrodynamic characteristics has been developed.

[3] While previous studies (discussed below) provide a good picture of the mean structure and characteristics of the

\footnotetext{
${ }^{1}$ Proudman Oceanographic Laboratory, Liverpool, UK.

${ }^{2}$ Now at British Antarctic Survey, Cambridge, UK.
}

Copyright 2007 by the American Geophysical Union. 0148-0227/07/2005JC003386\$09.00
Irish Sea, the variability on interannual timescales is poorly described. Studies of longer-term variability have been limited to climate studies of adjacent shelf waters and the northeast Atlantic, using general circulation models (GCMs) such as HadCM3 [e.g., Sheppard, 2004]. However, these models have an inadequate resolution for this region (for example, HadCM3 has a resolution of $1.25^{\circ}$ by $1.25^{\circ}$ ) so are unable to resolve many of the features of interest in the shelf seas such as regions of seasonal stratification and associated fronts. Moreover climate models often do not include some of the dominant physical processes such as tidal mixing and the benthic boundary layer. The aim of this work is to assess the performance of a fine-resolution regional model of the Irish Sea over a 40 year period, 1960-1999, and to use the model to examine the details of the seasonal and interannual variability of temperature and salinity.

[4] The hydrodynamics of the Irish Sea are dominated by the semidiurnal tide with tidal currents in most of the region of the order $1 \mathrm{~m} \mathrm{~s}^{-1}$. This ensures that much of the Irish Sea remains vertically well mixed throughout the year, with only sporadic stratification, for example in Liverpool Bay [Sharples and Simpson, 1995]. In contrast, to the west of the Isle of Man is a region of relatively deep water $(>100 \mathrm{~m})$ 
and tidal currents less than $0.3 \mathrm{~m} \mathrm{~s}^{-1}$. The combination of weak tides and deep bathymetry allows the western Irish Sea to stratify in spring and summer, since there is insufficient tidally generated turbulent energy to maintain mixing against the input of surface buoyancy through solar heating [Simpson, 1971; Simpson and Hunter, 1974]. Beneath the seasonal thermocline is a dome-shaped mass of cold, relict winter water that is left trapped and comparatively isolated after the onset of summer stratification. Associated with the margins of the dense bottom water pool are localized but intense baroclinic flows forming a midwater cyclonic gyre with along-front flows typically $\sim 0.2 \mathrm{~m} \mathrm{~s}^{-1}$ [Horsburgh et $a l ., 2000]$. A similar flow has also been identified at the Celtic Sea front [Horsburgh et al., 1998].

[5] Underlying these seasonal flows, observational work has suggested that, on timescales exceeding several months, there is a net northward flow out of the Irish Sea through the North Channel [e.g., Howarth, 1982; Brown and Gmitrowicz, 1995; Leonard et al., 1997]. Modeling studies have suggested that tidal residuals contribute about $0.02 \mathrm{~Sv}$ $\left(1 \mathrm{~Sv}=1 \times 10^{6} \mathrm{~m}^{3} \mathrm{~s}^{-1}\right)$ to this northward flux [Pingree and Griffiths, 1980; Proctor, 1981; Young et al., 2000]. In addition to this, the low-frequency nontidal flow is generally northward but is highly sensitive to the magnitude and direction of winds over the shelf [Howarth, 1982; Brown and Gmitrowicz, 1995; Knight and Howarth, 1999], as is the proportioning of water flowing to the east and west of the Isle of Man [Young et al., 2001].

[6] To illustrate the salinity distribution typically observed in the Irish Sea, Figure 2 shows the initial salinity field used in the model simulations (see caption for a description of its derivation). The horizontal gradients in salinity drive an estuarine-like residual circulation in the eastern Irish Sea [Heaps, 1972; Czitrom, 1986], and vertical gradients in tidal displacement allow stratification to develop near freshwater sources inshore, such as Liverpool Bay [Sharples and Simpson, 1995]. Detailed cruise data indicate a sharp transition between the fresher coastal waters (salinity $\sim 30$ practical salinity units (psu)) and more saline Irish Sea waters (salinity $\sim 34.2$ psu [e.g., Jones and Folkard, 1971]), with the frontal location determined by climatic influences such as river discharge and the strength and salinity of Celtic Sea inflows [Evans et al., 2003]. In the western Irish Sea, although salinity contributes to the early development of stratification near the Irish coast, once temperature stratification is developed salinity plays a relatively minor role [Horsburgh et al., 2000].

[7] To investigate the variability of temperature and salinity over a 40 year period we use a high-resolution regional model in conjunction with a range of observations. Such a simulation is inevitably highly dependent on its forcing (surface and lateral boundary conditions) and to address this we have gathered the best data sets available to us at the time; one of the objectives of this work is to assess this forcing and how it might be improved in the future.

[8] In the next section the model used for this study is described along with details of the required forcing data. In section 3 the results of the model-data comparisons are presented and the modeled seasonal and interannual variability is discussed. Section 4 considers the long-term variability in the temperature stratification in the western
Irish Sea. Finally, the results and conclusions are summarized in section 5 .

\section{Model Description}

[9] We use the Proudman Oceanographic Laboratory Coastal Ocean Modeling System (POLCOMS). This is a three-dimensional finite difference primitive equation model (described by Holt and James [2001]) formulated in spherical coordinates on an Arakawa [1972] B grid with a terrain following sigma coordinate system in the vertical (for this application). Key aspects of the numerical scheme include: calculation of vertical diffusivities for momentum and scalars using a Mellor-Yamada-Galperin level 2.5 turbulence closure scheme; calculation of horizontal pressure gradients by interpolation onto horizontal planes, which significantly reduces the numerical errors commonly found over steep topography in sigma coordinate models; and use of the "piecewise parabolic method" (PPM) [James, 1996] for the advection of state variables, which is a conservative scheme that minimizes numerical diffusion and has excellent front preserving properties. The ability of this model to reproduce the observed barotropic and baroclinic variability on the northwest European shelf has been demonstrated in a range of applications, including Proctor and James [1996], Holt and James [2001], Holt et al. [2001] and Holt and Proctor [2003].

[10] In this study, the model grid has a horizontal resolution of $1 / 20^{\circ}$ longitude by $1 / 30^{\circ}$ latitude $(\sim 3.5 \mathrm{~km})$, and has $25 \sigma$ layers in the vertical evenly distributed throughout the water column. The model bathymetry is derived from a fine-resolution (approximately $1 \mathrm{~km}$ ) bathymetry digitized from Admiralty Fair Sheets (where available) and Admiralty Charts supplied by the U.K. Hydrographic Office [Brown et al., 1999].

[11] The initial temperature field is from a winter climatology of the northwest European shelf (using Advanced High Resolution Radiometer (AVHRR) satellite observations; 1995-1997 data, following Holt and Proctor [2003]; a short period is used since this is unlikely to have much impact beyond the first model year). The initial salinity field is derived from climatological, winter salinity distributions of ICES data (Figure 2; G. Tattersall, Centre for Environment, Fisheries and Aquaculture Science (CEFAS), personal communication, 2003). At the open boundary, the model uses elevations and depth mean currents for 15 tidal constituents interpolated from an analysis of the POL Atlantic Margin model (see http://www.metoffice.gov.uk/research/ ncof/shelf/index.html). Hourly residual elevations and currents, which represent the far field forcing, are taken from a simulation of the POL storm surge model [Flather et al., 1991] for the 1960-1999 period. We use 6 hourly atmospheric pressures and surface winds interpolated from the Norwegian Meteorological office (DNMI) data, the same data set as used by the storm surge model, so ensuring consistency with the residual elevations and currents imposed at the open boundary. Spatially and temporally varying air temperature, relative humidity and cloud cover are interpolated from 6 hourly data provided by the National Centre for Environmental Prediction (NCEP, http:// www.cdc.noaa.gov/) [Kalnay et al., 1996]. Surface heat fluxes are then calculated using the bulk formulae discussed 


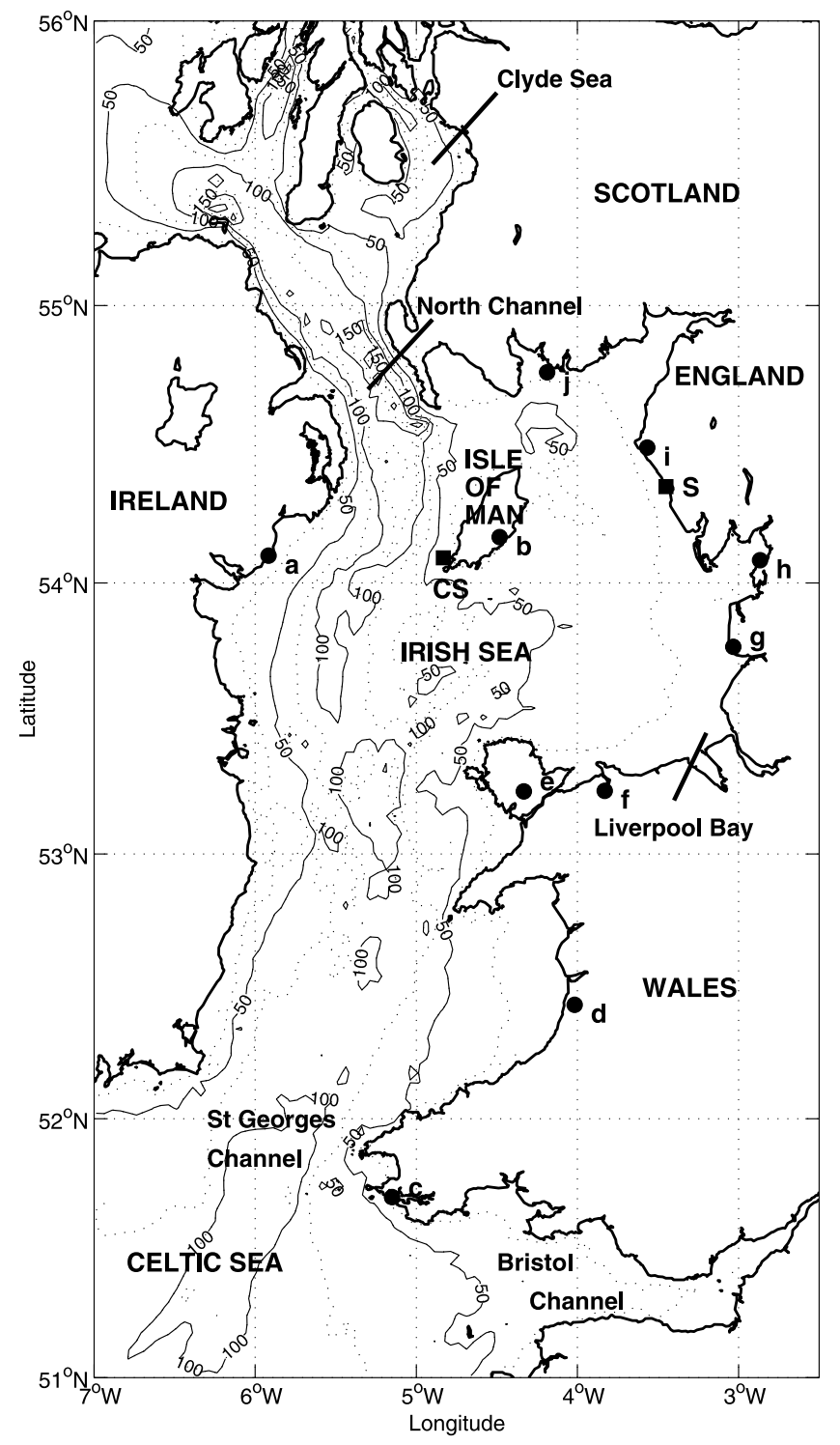

Figure 1. Map illustrating model bathymetry (depths in meters) and locations referred to in the text. CS is Cypris station; $\mathrm{S}$ is Sellafield; and a to $\mathrm{j}$ are locations of rainfall data.

by Gill [1982]. Short-wave solar radiation is calculated from equations describing the dependence of solar radiation on the position of the sun, adjusted for cloud cover (as described by Luyten et al. [1999]).

[12] Daily data from a 1998-2002 simulation of the POL Atlantic Margin model is averaged to provide a mean annual cycle of temperature and salinity along the model open boundaries. This model is in turn forced by ECMWF atmospheric data, flow data from 38 major rivers and oceanic data from the UK Met Office's $1 / 3^{\circ}$ Forecast Ocean Assimilation Model (FOAM) [Bell et al., 2000]. The boundary condition temperature and salinity data are used in an upwind advective boundary condition that employs the imposed currents to update temperature and salinity at the open boundary grid cells. Although the use of boundary condition data from a short period is not ideal, there are insufficient observations available from which to derive spatially and temporally varying boundary forcing for the model. The potential impact of the representation of the open boundary salinity and temperature on model results is discussed in section 3 .

[13] To accurately simulate the salinity it is important to adequately represent freshwater inputs from precipitation and river flows. There are insufficient long-term rainfall data to derive spatially varying precipitation fields for the forty year hindcast simulation. Instead daily precipitation rates are estimated by averaging the available data (held at the British Atmospheric Data Centre) from 10 sites around the Irish Sea coast (sites a-j, Figure 1) to produce a single time series. Evaporation rates are calculated using the evaporative loss term of the bulk heat flux formulae. Previous applications of POLCOMS to the northwest European shelf region have used daily discharge data from a small number (36) of European rivers to provide the riverine inputs [e.g., Holt and James, 2001]. While this provides a first estimate of river discharge it is not adequate for accurately modeling the salinity in the Irish Sea and here we use the dense network of gauging stations (currently around 1400) around Britain. However, the density of these stations varies considerably from region to region with relatively few stations in remote (e.g., western Scotland) or technically more challenging areas (e.g., in the flat terrain of East Anglia). Thus direct measurements account for only around $65 \%$ of the outflow from Great Britain [Marsh and Sanderson, 2003]. To obtain a more accurate representation of freshwater flows, some estimate of the contribution from the ungauged areas is required, including consideration of major rivers in ungauged basins, minor streams draining directly to the sea, groundwater outflows, and in a few areas (e.g., the Thames estuary) sewage effluent. Researchers at the Centre for Ecology and Hydrology (CEH), Wallingford, have developed an adjustment technique based on the observed association between river flow and catchment size [Marsh and Sanderson, 2003]. In summary, the method requires the identification of basic areal units (hydrometric areas) for which outflows need to be aggregated; 83 are needed for this model domain. For each of these, representative index catchments are identified and weighting factors are derived to allow for those outflows that are not measured. These take the initial first-order estimates of runoff based on catchment size and further refine them by weighting according to a relation between mean runoff from the gauged and ungauged areas. The resulting weighting factors are used as multipliers for the gauged river data. Daily data for the full 40 year period are not available for all the gauged rivers, so a mean annual cycle is calculated for each gauged river from the available data and this is used to fill any gaps. The data set as a whole is about $76 \%$ complete, with about $93 \%$ coverage after 1980 .

[14] The model simulation is conducted for the period 1960-1999 and the ability of the model to accurately reproduce the long-term variability of temperature and salinity is assessed by comparison with observational data. For evaluation of model performance, an extensive data set of conductivity-temperature-depth (CTD) observations collected in the modeled region (Figure 1). Over this period has been obtained from the British Oceanographic Data Centre (BODC), amounting to 3397 CTD profiles. In addition, since 1954 data have been collected by the Port Erin Marine 


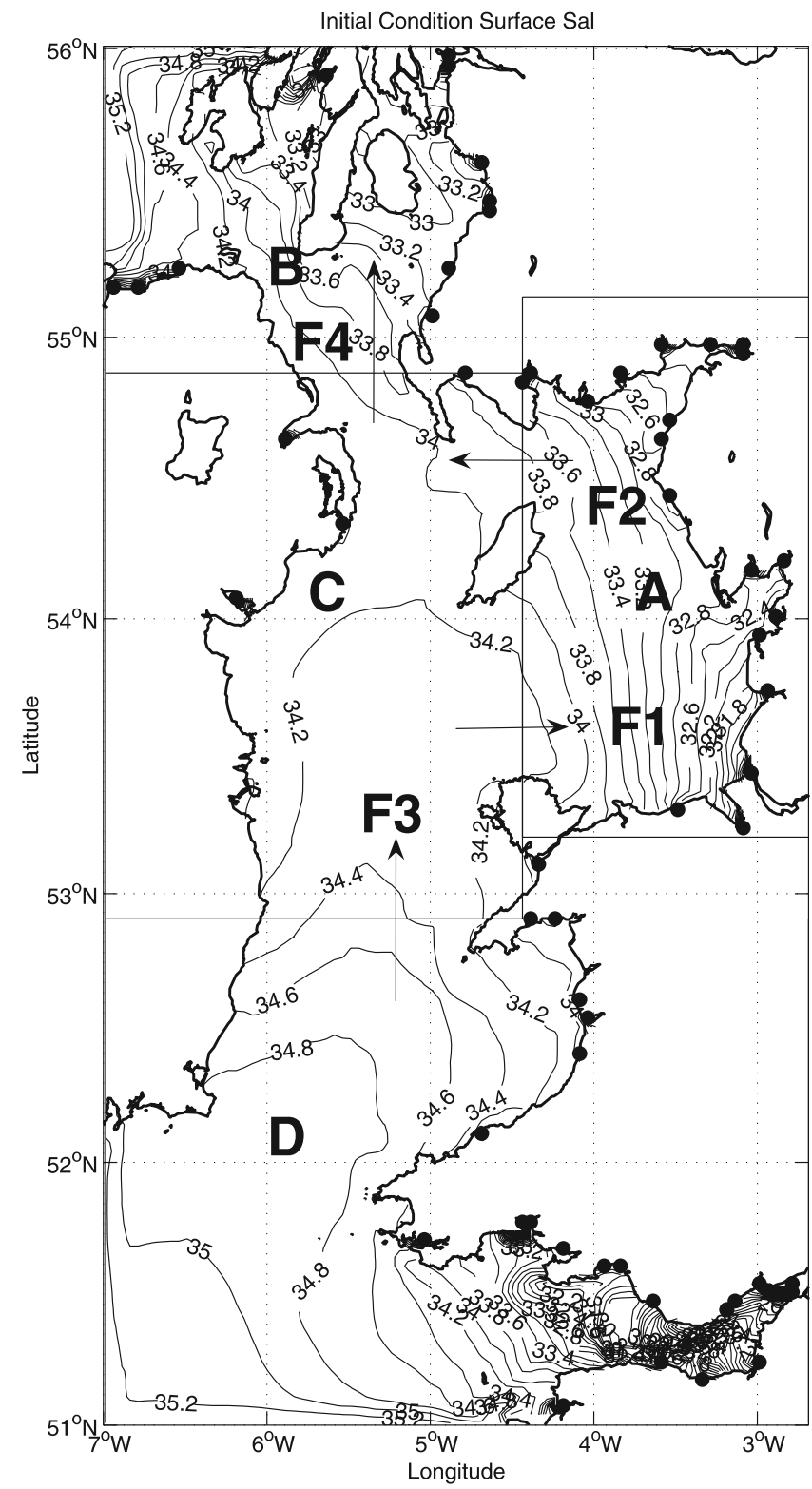

Figure 2. Salinity initial condition (psu) derived from December-March ICES data for 1960-2000 (G. Tattersall, CEFAS, personal communication, 2003). Also shown are the regions $(\mathrm{A}-\mathrm{D})$ used for area mean time series and statistics. Solid circles show the location of the 83 riverine sources of freshwater used. Arrows labeled F1 to F4 indicate sections used for flux calculations in Table 3.

Laboratory (PEML; Liverpool University) at a fixed sampling point (Cypris station) approximately $5 \mathrm{~km}$ off the southwest coast of the Isle of Man (Figure 1). These data comprise samples at $5 \mathrm{~m}$ intervals through the water column, taken at fortnightly intervals, and analyzed for physical parameters, nutrients, and chlorophyll; these are a highly valuable resource for understanding long-term changes in this region.

[15] In addition to an overall assessment of model accuracy, available CTD data are used to investigate any longterm drift in model errors over the 40 year simulation, and the geographical distribution of these errors. Unlike many other simulations this model does not relax salinity to a seasonal climatology. As demonstrated below we find a consistent tendency to overestimate the (absolute) salinity, so in addition to the standard model run we conduct a series of model experiments aimed at identifying the causes of this: (1) an experiment without surface salinity forcing, (2) an experiment with no boundary residual currents or elevations, and (3) an experiment with increased (doubled) river discharges.

\section{Temperature and Salinity Results}

\subsection{Temperature}

[16] The comparison of observed and modeled temperatures for the period 1960-1999 is shown in Figure 3 (3397 CTD profiles) with a summary of the statistics given in Table 1. Here, for each observed value a modeled temperature was extracted from the daily mean fields at the vertical level whose depth range included that of the observed value. The model accurately reproduces the observed temperatures throughout the model's domain over the 40 year period with overall mean and RMS errors of $-0.01^{\circ} \mathrm{C}$ and $0.78^{\circ} \mathrm{C}$, respectively. The spatial distribution of model errors (Figures $3 \mathrm{a}$ and $3 \mathrm{~b}$ ) shows no obvious pattern; in particular shallow regions do not show a substantial increase in error as might be expected from a significant inaccuracy in the heat flux calculation; there is no significant correlation between water depth and mean or RMS error. The temporal variability in model errors (not shown) demonstrates no obvious drift in model accuracy over the 40 year period.

[17] As a more detailed assessment of the model's ability to reproduce long-term variability, Figure 4 shows a comparison of modeled (daily mean) and observed near-surface temperatures at Cypris station; the latter observations include sea surface temperatures (SST) derived from AVHRR satellite measurements. It can be seen that the model succeeds in simulating the observed seasonal and interannual variability at Cypris station, with a slight tendency to underpredict the observed winter temperatures $\left(\sim 0.5^{\circ} \mathrm{C}\right)$. The Cypris station is located in a well-mixed region thus these results are representative of the whole water column. A comparison of modeled and observed spectra of monthly mean temperature at Cypris Station (Figure 5) clearly illustrates the ability of the model to reproduce observed temperature variability over intra and interannual timescales. There is close agreement between the two spectra for periods up to $\sim 20$ years. However, at longer periods the model tends to underpredict the variability. Also shown on Figure 5 is the correlation between monthly mean modeled and observed temperatures after both have been low-pass filtered for a range of cutoff periods (from 0.3 to 20 years). It is evident for the whole range of cutoff periods (from intra-annual to interannual and decadal) that the model and observations are well correlated. There is some variation though, notably a drop in correlation once the annual cycle has been filtered out, indicating that this is the most accurately modeled frequency. The correlation then gradually increases indicating that the trend is more accurately modeled than variability on $2-10$ year scales.

[18] These results demonstrate that the regional-scale model is able to reproduce the long-term variability in temperatures in the Irish Sea. We now investigate in further 
A)

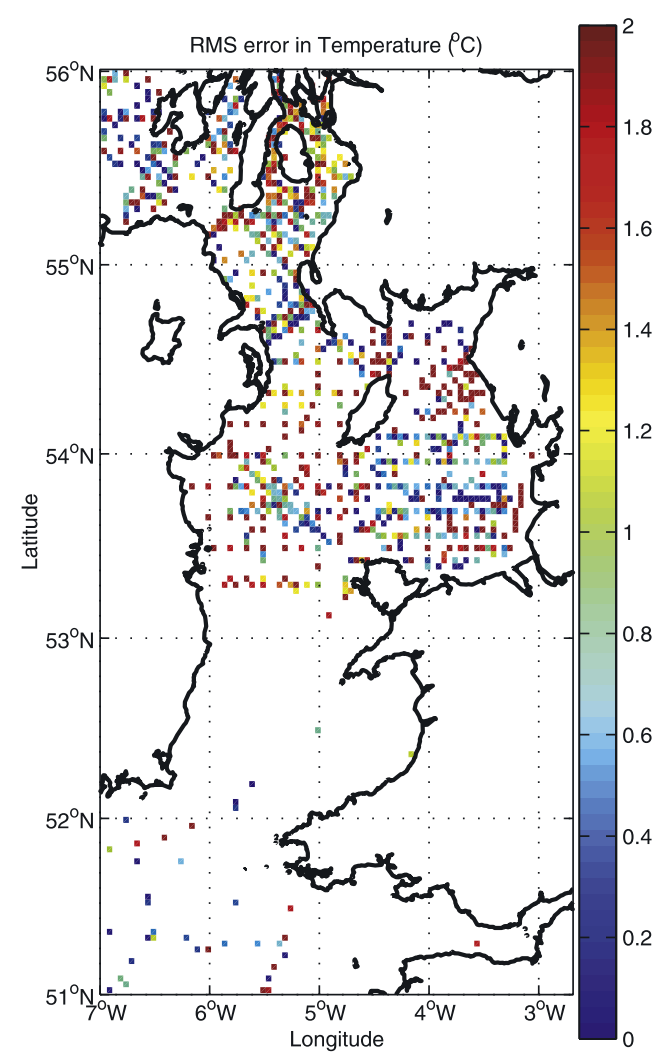

B)

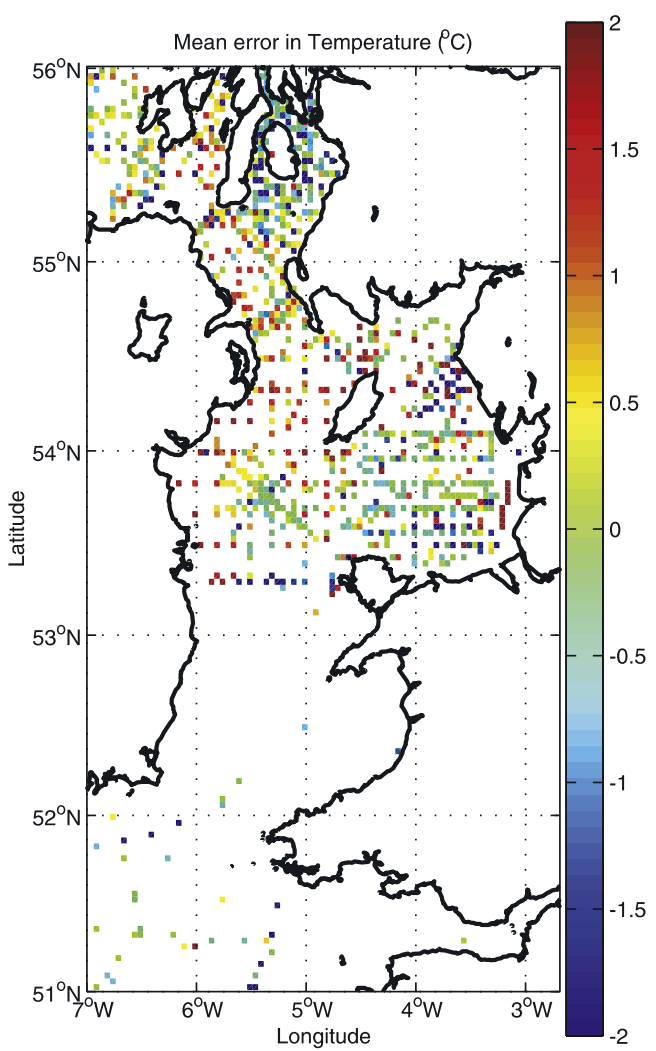

C)

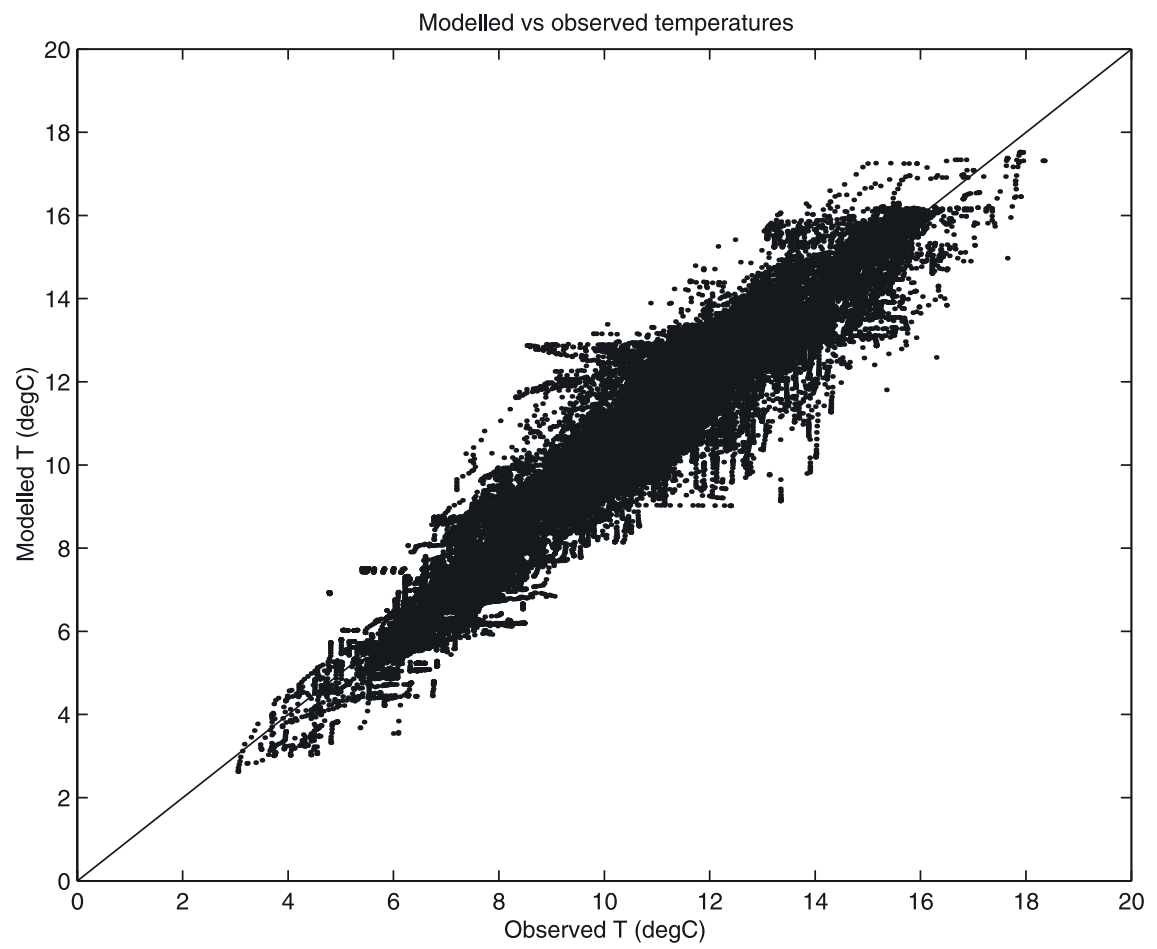

Figure 3. Comparison of modeled and observed temperatures for the period 1960-1999 (3397 CTD profiles). 
Table 1. Statistical Comparison of Observed and Modeled Temperatures and Salinities for the Simulated Period, 1960-1999 ${ }^{\text {a }}$

\begin{tabular}{llc}
\hline \hline & \multicolumn{2}{c}{ Temperatures } \\
\cline { 2 - 3 } & Mean, ${ }^{\circ} \mathrm{C}$ & $\mathrm{RMS},{ }^{\circ} \mathrm{C}$ \\
\hline All points & -0.01 & 0.78 \\
Near-surface & -0.08 & 0.71 \\
Near-bed & 0.00 & 0.86 \\
\hline & \multicolumn{2}{c}{ Salinity } \\
\cline { 2 - 3 } & Mean, psu & RMS, psu \\
\hline All points & 0.79 & 0.98 \\
Near-surface & 0.81 & 0.99 \\
Near-bed & 0.78 & 0.96 \\
\hline \hline
\end{tabular}

${ }^{\text {a } T h e r e ~ a r e ~} 3397$ CTD profiles. Results are presented as mean error and root mean square (RMS) error.

detail the ability of the model to reproduce the observed long-term warming trend. Figure 6 shows the variation of summer and winter mean temperature anomalies in the model and the Cypris station observations. Linear warming trends are given in Table 2 for Cypris station and the four regions (A, B, C and D) shown in Figure 2. This shows there is statistically significant warming of the summer months in all regions, amounting to $\sim 0.4^{\circ} \mathrm{C}$ during these forty years. The warming in winter is typically much smaller to the extent that it is generally of similar order to the uncertainty in the calculation, the only exception being in region A (eastern Irish Sea) where it is similar to the summer warming. This pattern of summer warming being substantially greater than winter is repeated at Cypris station in both model and observations, and the difference between the two is similar to the uncertainties quoted for the regional mean values. In winter, the linear warming trend scales approximately inversely with the mean water depth of the regions, indicating that it results from a change in heat flux. In summer, this is less obvious as regions $\mathrm{A}, \mathrm{B}$ and $\mathrm{C}$ all heat at approximately the same rate despite region $\mathrm{A}$ being substantially shallower than $\mathrm{B}$, which also remains well mixed. This deserves further investigation through a detailed analysis of how the terms in the heat flux equation vary over this period, which is beyond the scope of the present work. It is interesting to note that of all the longterm time series around the European shelf examined in the NOWESP project [Visser et al., 1996] the Cypris station data shows arguably the most obvious long-term warming

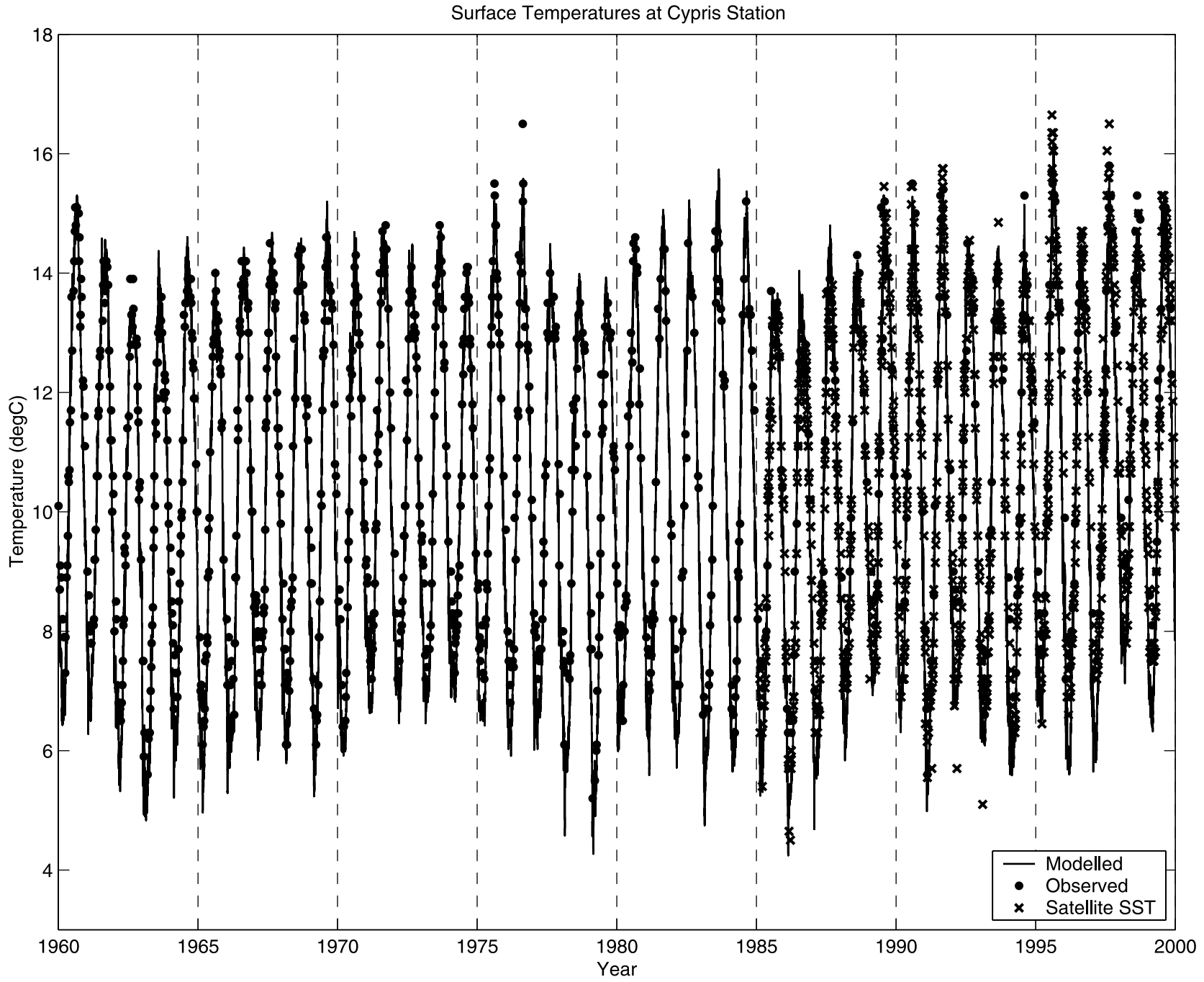

Figure 4. Comparison of modeled and observed near-surface temperatures at Cypris station over the period 1960-1999. 

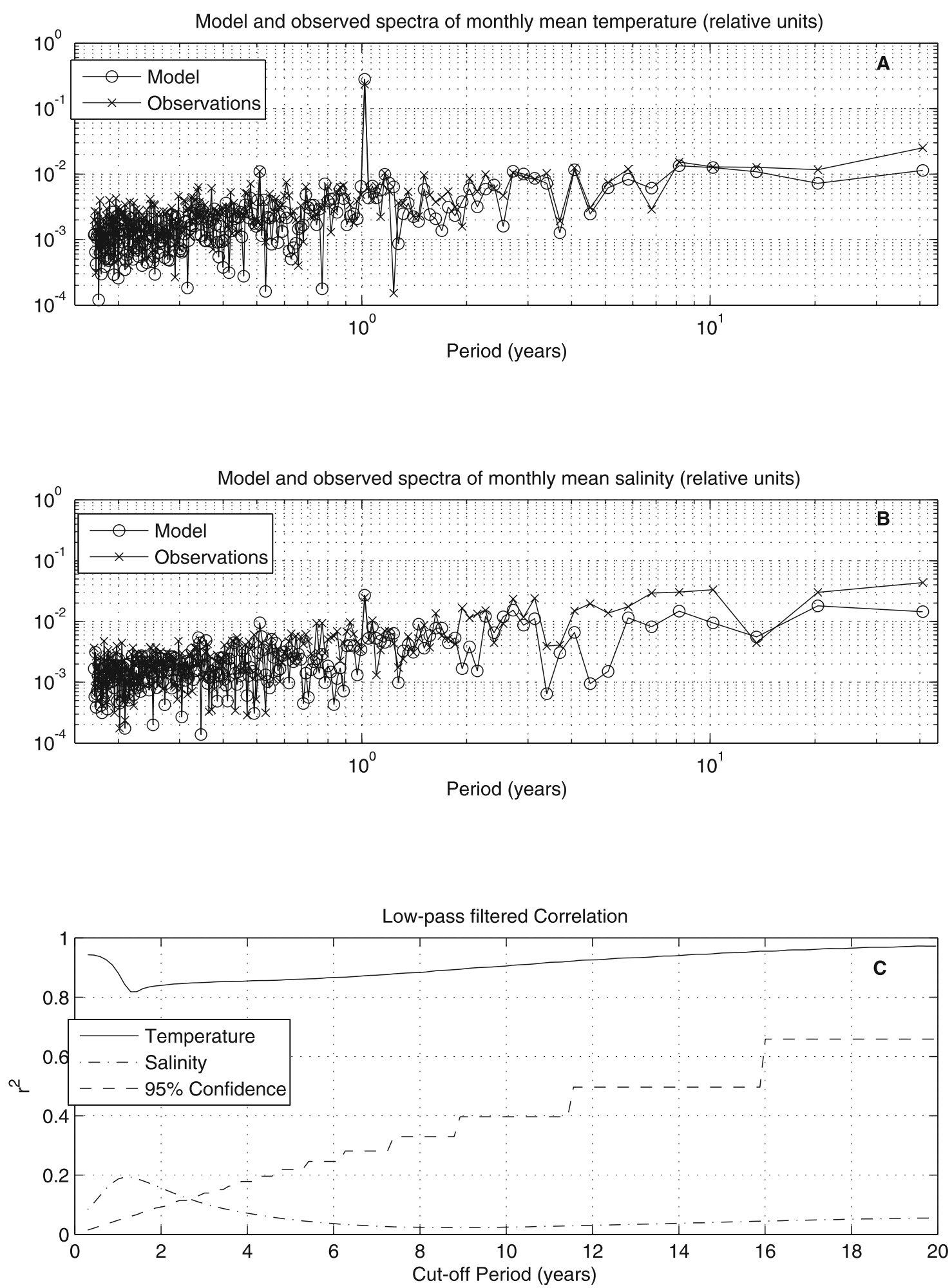

Figure 5. Analysis of monthly mean temperature and salinity at Cypris station: (a) model and observed temperature spectra, (b) model and observed salinity spectra, (c) low-pass filtered correlation between model and observed temperature and salinity varying with filter cutoff period. The $95 \%$ confidence limit is calculated from the number of data points remaining above the cutoff period.

trend. Table 2 also shows the linear trend for the period 1976-1999, demonstrating the warming is consistently greater during this period and, apart from region $\mathrm{A}$ in winter, all areas show a warming comparable to the IPCC estimate of northern hemisphere SST warming of $0.018^{\circ} \mathrm{C}$ $\mathrm{yr}^{-1}$ for this period [Intergovernmental Panel for Climate Change, 2001].

[19] That the temperature warming trend is well reproduced with mean open boundary temperatures suggests these have relatively little influence over most of this model 

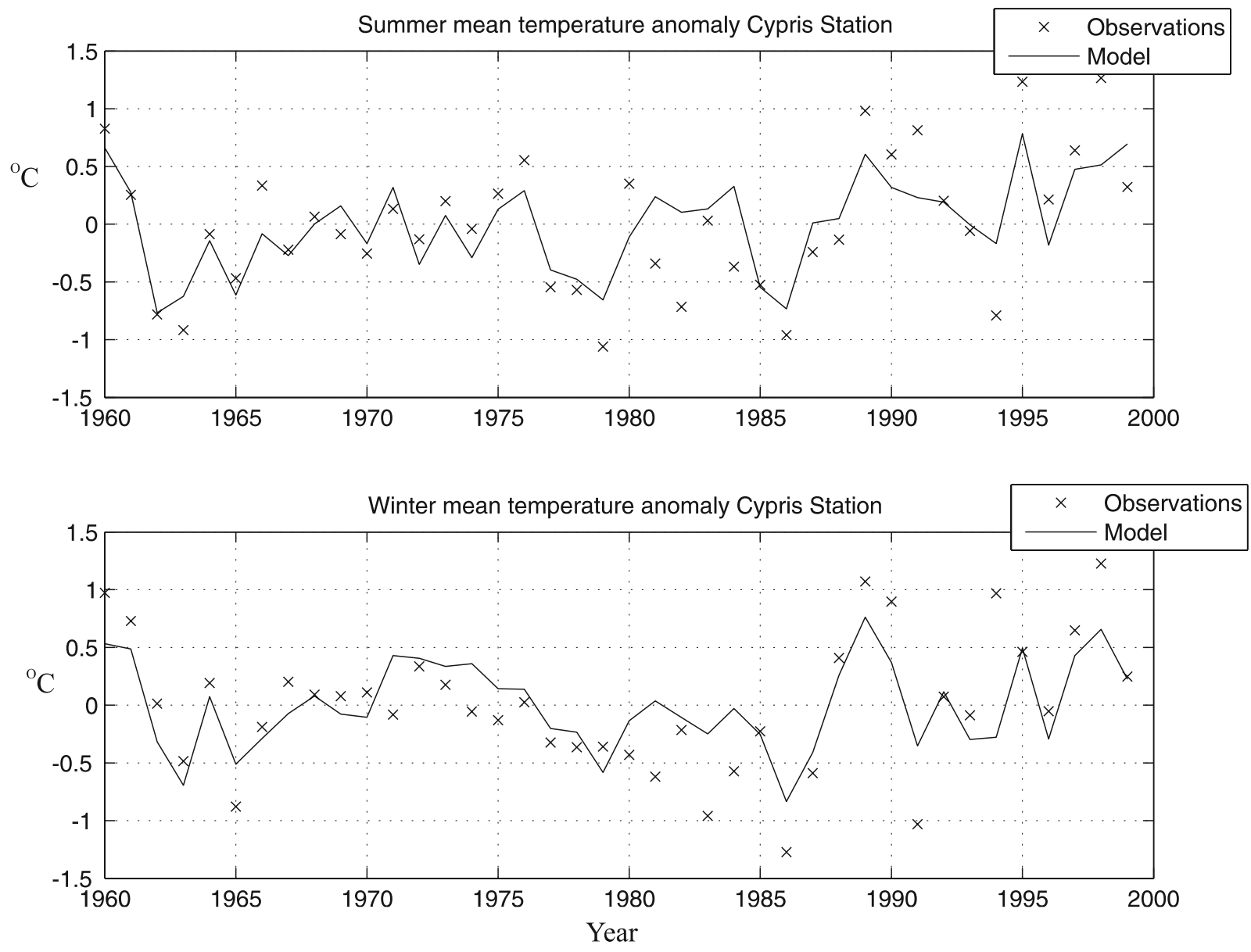

Figure 6. Summer (May-October) and winter (November-April) mean temperatures at Cypris station.

domain and thus it can be concluded that temperature variability in the Irish Sea is driven predominantly by local forcing. This is to be expected as the flushing time of the Irish Sea is typically 1-2 yrs (Department for Environment, Food, and Rural Affairs, Quality status report of the marine and coastal areas of the Irish Sea and Bristol Channel 2000, chapter 2: Geography and physical oceanography, http:// www.defra.gov.uk/environment/water/marine/uk/science/ irishbristol/03.htm), which is considerably longer than the response to seasonally varying meteorological forcing. Holt and Proctor [2003] demonstrate that horizontal temperature advection cannot be neglected within the Irish Sea, but also that it has a comparatively minor influence in the Celtic Sea and on the Malin shelf. However, the fixed annual cycle boundary conditions may explain why region D (southern
Irish Sea and Celtic Sea) shows the lowest warming trend of all the regions.

\subsection{Salinity}

[20] The comparison of observed and modeled salinity is shown in Figure 7 with a summary of the statistics given in Table 1. With overall mean and RMS errors in salinity of $0.79 \mathrm{psu}$ and $0.98 \mathrm{psu}$, respectively, it can be seen that the model does not reproduce the observed salinities as accurately (in fractional terms) as the temperatures and is consistently too saline. As with temperatures, there is no significant drift in model predictions over the 40 year period which is particularly promising given that the model does not relax to climatology. The spatial distribution of salinity errors shows the salinity is uniformly overestimated across this region and that the largest errors occur in the coastal

Table 2. Linear Rates of Warming of the Depth Mean Temperature in the Four Regions Shown in Figure 2 and at Cypris Station

\begin{tabular}{|c|c|c|c|c|c|}
\hline \multirow[b]{2}{*}{ Region } & \multirow[b]{2}{*}{ Mean depth, m } & \multicolumn{2}{|c|}{$\begin{array}{l}\text { Summer Warming, } \\
\text { deg } \mathrm{C} \mathrm{yr}^{-1} \times 10^{-3}\end{array}$} & \multicolumn{2}{|c|}{$\begin{array}{l}\text { Winter Warming, } \\
\text { deg } \mathrm{C} \mathrm{yr}^{-1} \times 10^{-3}\end{array}$} \\
\hline & & $1960-1999$ & 1976-1999 & $1960-1999$ & 1976-1999 \\
\hline A & 24.5 & $12 \pm 6$ & $29 \pm 12$ & $11 \pm 6$ & $36 \pm 11$ \\
\hline B & 61.1 & $10 \pm 3$ & $22 \pm 6$ & $3 \pm 4$ & $16 \pm 7$ \\
\hline $\mathrm{C}$ & 62.1 & $12 \pm 4$ & $26 \pm 9$ & $4 \pm 5$ & $19 \pm 9$ \\
\hline $\mathrm{D}$ & 60.5 & $7 \pm 3$ & $14 \pm 6$ & $5 \pm 3$ & $14 \pm 7$ \\
\hline Cypris (observation) & 31.8 & $15 \pm 8$ & $49 \pm 17$ & $6 \pm 8$ & $51 \pm 17$ \\
\hline Cypris (model) & 31.8 & $13 \pm 5$ & $30 \pm 10$ & $3 \pm 5$ & $22 \pm 11$ \\
\hline
\end{tabular}


regions, as might be expected since these regions show the greatest salinity variability due to freshwater inputs. Examining the geographical distribution of errors, it is found that the maximum errors occurred around the Scottish islands, in particular the Clyde Sea and associated lochs, the Bristol Channel and the eastern Irish Sea. The largest errors can be grouped as illustrated in Figure 7c, where each group corresponds to a particular year. The largest errors in the eastern Irish Sea occurred in 1986 (22-26 August; group 1), along with some of the largest errors around Scotland. All observations in the Bristol Channel are from a single location in 1995 (group 2a) and 1996 (group 2b), and all show large errors.

[21] It is not surprising that the seas around Scotland, and in particular the Clyde Sea, are not so well modeled, owing to the complexity of the coastline and bathymetry of the fjordic systems found here. There is also added uncertainty in the flow weighting due to the limited river gauging in Scotland. In particular, the hydrometric area that discharges into the western Clyde Sea has no gauging stations and flows are entirely constructed from data from neighboring areas. However, it is not clear why the period 22-26 August 1986 is particularly poorly modeled. Large uncertainties in the Bristol Channel are unlikely to be due to errors in the river inputs since the southwest of England has a relatively dense gauging network. However, inadequate representation of the channel coastline and horizontal dispersion by the $3.5 \mathrm{~km}$ grid are likely to adversely affect the model results. Moreover this version of POLCOMS does not include a wetting and drying algorithm, thus a minimum water depth of $10 \mathrm{~m}$ is prescribed. In regions of high tidal range and shallow depth the salinities will be overestimated, even if the river flux is accurate, because of the increased volume of (saline) water in the model. In the Bristol Channel and near coastal regions of the eastern Irish Sea the tidal range exceeds $8 \mathrm{~m}$ and there are extensive tidal flats. In these regions the prescribed depth is significantly deeper than the actual bathymetry, and this is likely to be a significant source of error in the salinity. However, this is unlikely to directly affect the salinity further offshore, so long as the water is well mixed, but is likely to have a significant effect on the tidal currents [Proctor, 1981].

[22] A comparison of modeled and observed near-bed salinities at Cypris station is shown in Figure 8 (again these results are representative of the whole water column). The high-frequency variability in the daily data makes comparison and interpretation difficult, so Figure 8 shows monthly mean salinities, with the annual mean overlaid. During the first $1-2$ years the modeled salinity rises rapidly from the initial condition and is generally too saline for the rest of the model run. The observations show a general decline in salinity from 1960s - 1970s and a rise in the 1990s (as noted by Evans et al. [2003]); the observed spectra of monthly mean salinity (Figure 5) show that interannual variability is at least as strong as the seasonal signal in salinity. This longterm (decadal) shift is not seen in the model. However, the intra-annual variability is only marginally underestimated by the model (overall standard deviations are 0.25 and 0.15 in observations and model respectively) and many of the observed trends in shorter timescale interannual variability are reproduced. The differences in salinity from one year to the next agree in sign for $74 \%$ of this period and when they disagree the change is typically smaller than when they agree (on average 0.09 psu compared with 0.22 psu when they agree). A comparison of modeled and observed spectra of monthly mean salinity (Figure 5) further illustrates this. It is evident that on timescales of up to 2-3 years, the model variability compares well with that observed, but at longer timescales the model significantly underestimates the variability. This is born out by the correlation analysis which shows a statistically significant correlation (at the 95\% level) between model and observed salinities when they are low-pass filtered with a cutoff period less than $\sim 2.7$ years. The correlation rapidly decreases for longer cutoff periods and is no longer significant. This suggests that, while the model may not reproduce the absolute values of observed salinity, it contains the dominant physical processes for the simulation of salinity variability at intra and short-term interannual timescales. It should be born in mind that because Cypris station is located at the edge of the eastern Irish Sea salinity gradient, observations of salinity variability here are particularly dependent on any displacement of this gradient [Evans et al., 2003].

[23] To investigate the causes of the overestimation of salinity and the poor representation by the model of longterm variability in the observed salinity at Cypris station we turn to a number of sensitivity experiments and an analysis of the salinity budget in the model. The evolution of the volume averaged salinity of a region, $\bar{S}$, is described by

$$
\frac{d \bar{S}}{d t}=\frac{1}{V}\left(F_{A}-\bar{S}\left(Q_{R}+Q_{P}\right)\right) ; F_{A}=\iint \mathbf{u}(S-\bar{S}) d z \cdot d \mathbf{s}
$$

where the "anomaly" flux, $F_{\mathrm{A}}$, is integrated through the water column and around the boundary surrounding the region. The three terms in equation (1) (describing advective, riverine $\left(Q_{\mathrm{R}}\right)$ and surface $\left(Q_{\mathrm{P}}\right)$ changes in salinity) have been evaluated (Table 3 ) for the eastern and central Irish Sea (regions A and C, Figure 2) for the first two model years (1960-1961). This analyzes the evolution from the initial condition, a period of substantial salinity increase in the model at Cypris station. In the eastern Irish Sea (region A) it is immediately apparent that there is a close balance between large advective $\left(F_{A} / V\right)$ and freshwater fluxes, leaving a small tendency term $(d \bar{S} / d t)$. This suggests that any shift in this balance can have a substantial effect on the salinity evolution.

[24] There are four main influences on the long-term salinity simulation, namely: (1) evaporation-precipitation (E-P) balance, (2) freshwater inputs, (3) volume flux through the Irish Sea, and (4) far field variability in salinity.

[25] The experiments described in section 2 focus on the first three of these on the assumption that absolute variations in oceanic salinity are comparatively small (this is given some justification below). Figure 9 shows the effects of the three model experiments on surface salinity averaged from 1980 to 1989 . Surface salinity forcing is seen to have a significant influence; Figure $9 \mathrm{~b}$ shows that excluding this term increases the surface salinity by between $\sim 0.2 \mathrm{psu}$ in the southern and northern model regions and $\sim 0.8 \mathrm{psu}$ in the eastern Irish Sea. Hence the inclusion of E-P has a significant influence on reducing the general overprediction of salinity in the model; this is borne out by the results in 
A)

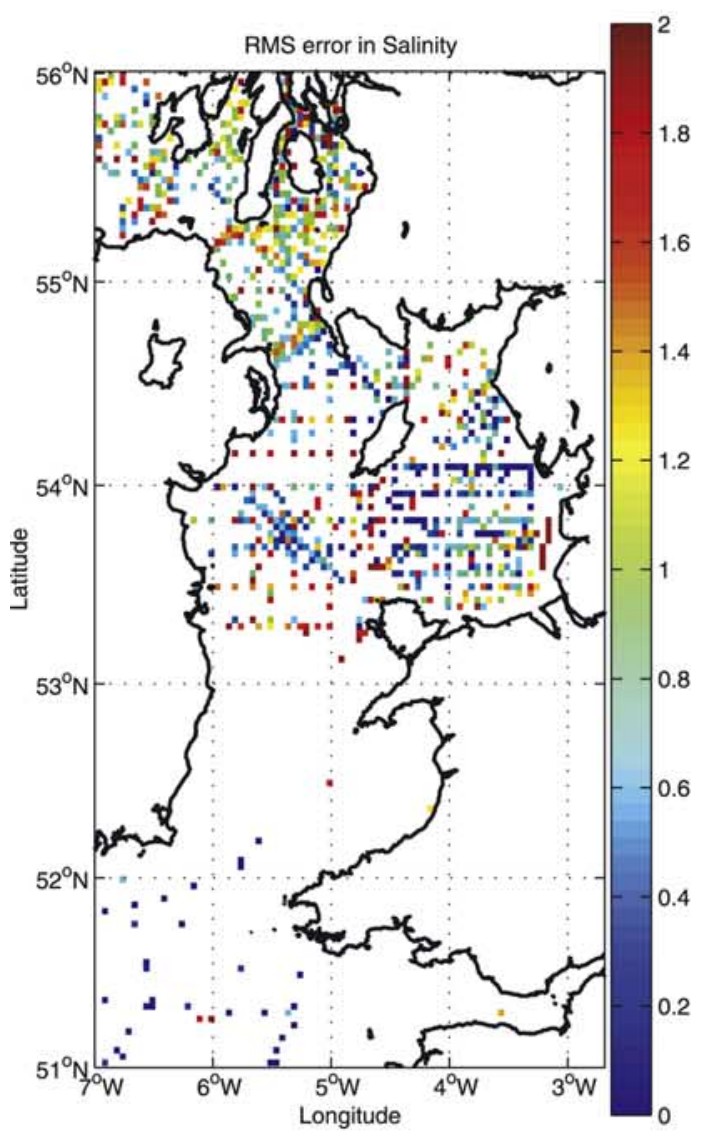

B)

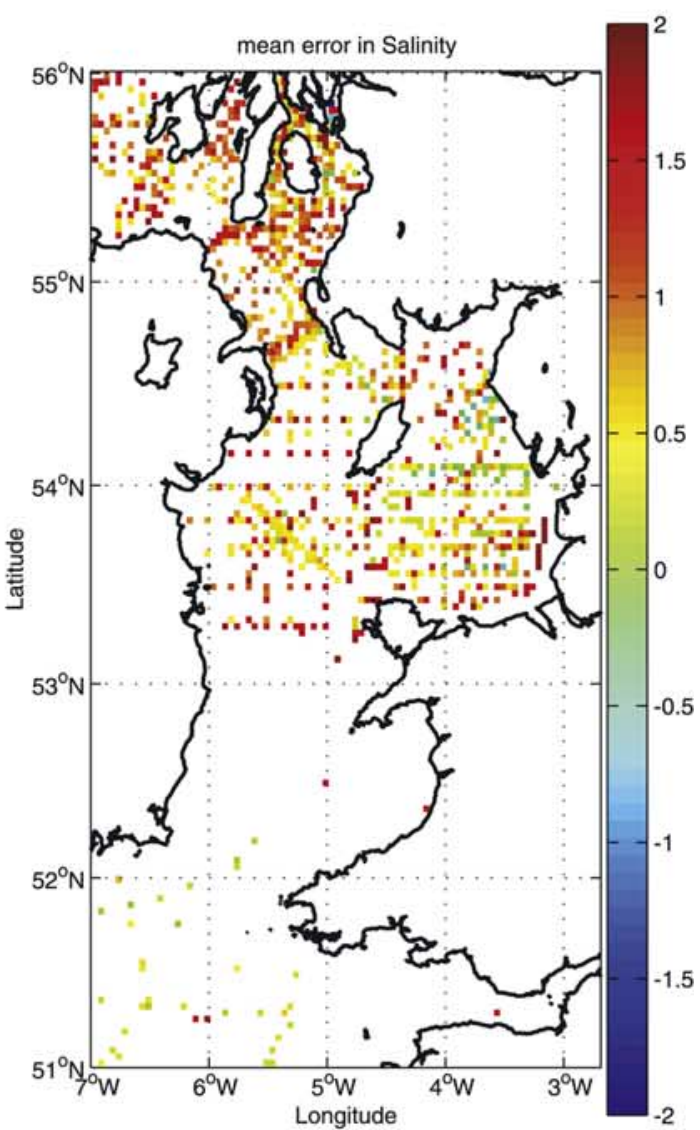

C)

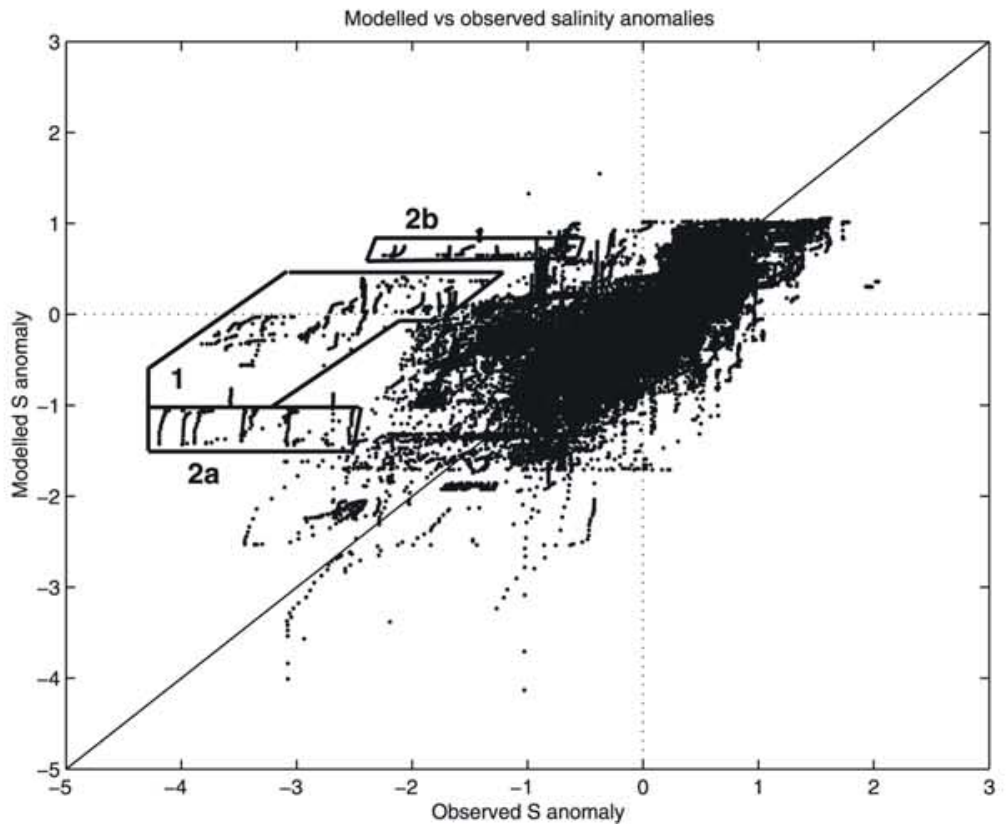

Figure 7. Comparison of modeled and observed salinities for the period 1960-1999 (3397 CTD profiles): (a and b) spatial distribution of errors and (c) anomalies (relative to the respective 40 year means). Group 1 is eastern Irish Sea and Scotland, 22-26 August 1986; group 2a is Bristol Channel, 1995; group 2b is Bristol Channel, 1996. 


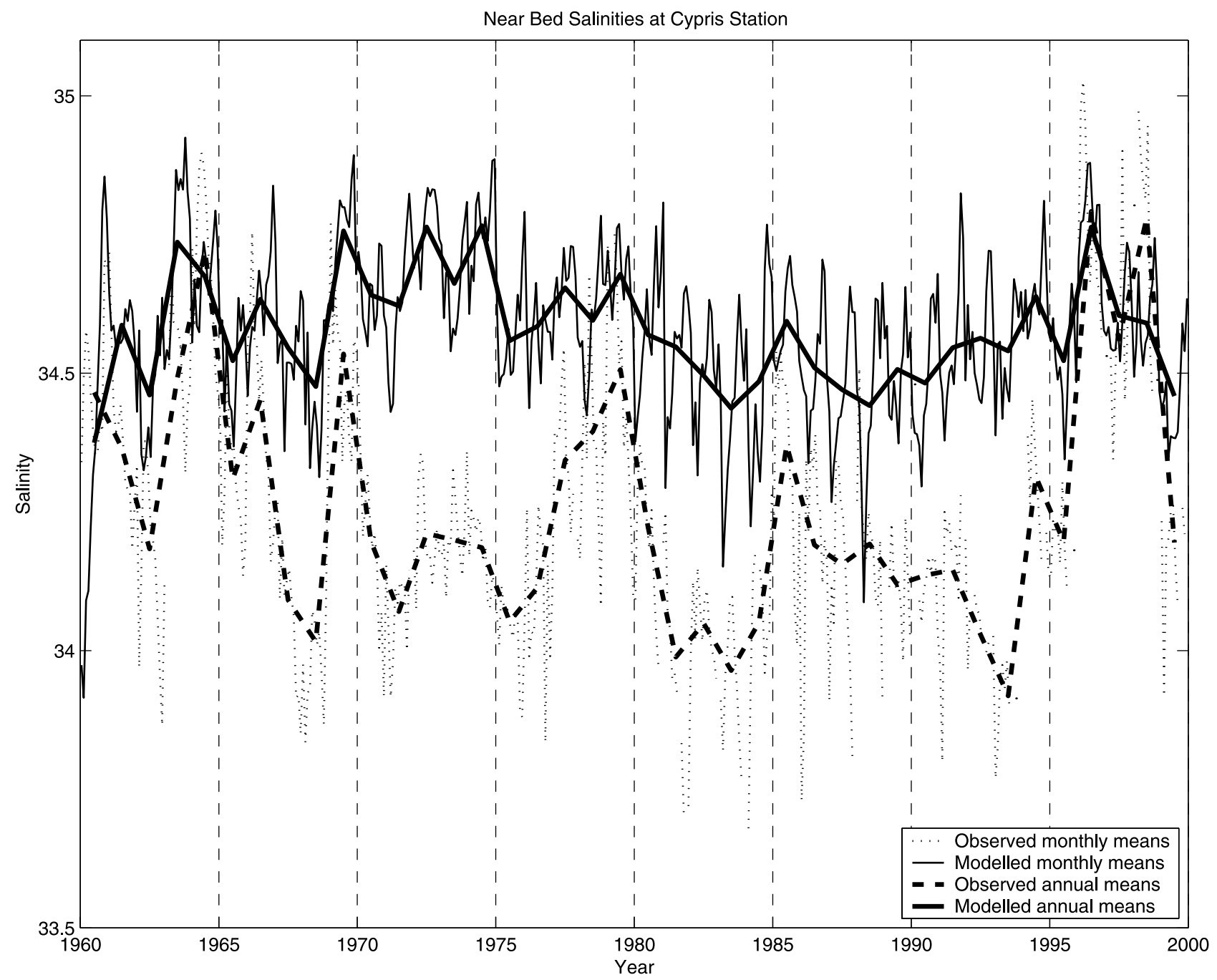

Figure 8. Comparison of modeled and observed mean monthly and mean annual near-bed salinities (psu) at Cypris station over the period 1960-1999.

Table 3 which show surface forcing tends to reduce the salinity of both regions $\mathrm{A}$ and $\mathrm{C}$. As discussed in section 2, precipitation in the model is temporally varying, but spatially constant. The effect of neglecting the spatial variability of precipitation is not clear, however, it is unlikely to greatly contribute to the variability in salinity on decadal timescales, since these are much longer than the flushing time. The decadal variability in precipitation is reasonably well prescribed in the model simulation through 10 obser- vational stations and given that these are coastal stations they would, if anything, tend to overestimate the precipitation in open seas. Moreover there is no correlation between annual mean salinity at Cypris station and the precipitation data. This leaves the possibility of a systematic error in the evaporation calculation. However, this would not influence the salinity errors in the Bristol Channel where E-P effects are small. Hence it is unlikely that surface salinity forcing is the main source of error in the model salinities.

Table 3. Terms in the Equation for Area Integrated Salinity (Equation (1)) for Regions A and C (Figure 2) From 1960 to 1961 in Experiment 1 (Standard Model) and 2 (No Boundary Residual) ${ }^{\mathrm{a}}$

\begin{tabular}{|c|c|c|c|c|c|c|c|c|c|c|c|}
\hline \multirow[b]{2}{*}{ Region } & \multirow[b]{2}{*}{$\begin{array}{c}d \bar{S} / d t \\
\mathrm{psu}^{-1} \mathrm{yr}^{-1}\end{array}$} & \multirow[b]{2}{*}{ 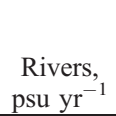 } & \multirow[b]{2}{*}{$\begin{array}{c}E-P \\
{\text { psu } \mathrm{yr}^{-1}}^{-1}\end{array}$} & \multicolumn{2}{|c|}{ F1 } & \multicolumn{2}{|c|}{$\mathrm{F} 2$} & \multicolumn{2}{|c|}{ F3 } & \multicolumn{2}{|c|}{ F4 } \\
\hline & & & & $\begin{array}{c}F_{A} / V, \\
\text { psu, } \mathrm{yr}^{-1}\end{array}$ & $\begin{array}{l}Q, \\
10^{3} \mathrm{~m}^{3} \mathrm{~s}^{-1} \\
\end{array}$ & 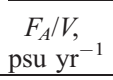 & $\begin{array}{c}Q, \\
10^{3} \mathrm{~m}^{3} \mathrm{~s}^{-1} \\
\end{array}$ & 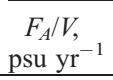 & $\begin{array}{c}Q, \\
10^{3} \mathrm{~m}^{3} \mathrm{~s}^{-1} \\
\end{array}$ & 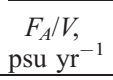 & $\begin{array}{c}Q, \\
10^{3} \mathrm{~m}^{3} \mathrm{~s}^{-1} \\
\end{array}$ \\
\hline A-1 & 0.40 & -1.79 & -0.75 & 1.90 & 29 & 1.04 & 29 & NA & NA & NA & NA \\
\hline A-2 & 0.53 & -1.79 & -0.74 & 2.07 & 31 & 1.00 & 32 & NA & NA & NA & NA \\
\hline C-1 & 0.17 & -0.10 & -0.37 & -0.16 & 29 & -0.74 & 29 & 0.49 & 44 & 1.06 & 44 \\
\hline C-2 & 0.24 & -0.10 & -0.37 & -0.20 & 31 & -0.74 & 32 & 0.68 & 96 & 0.99 & 96 \\
\hline
\end{tabular}

${ }^{a}$ Advective terms ("anomaly fluxes," $F_{A} / V$ ) are shown for the four sections F1, F2, F3, and F4 (Figure 2) along with the corresponding volume flux. The sense of each salinity term is with respect to the salinity in that region, whereas the volume fluxes are in the direction of the arrows in Figure 2. NA means not applicable. 

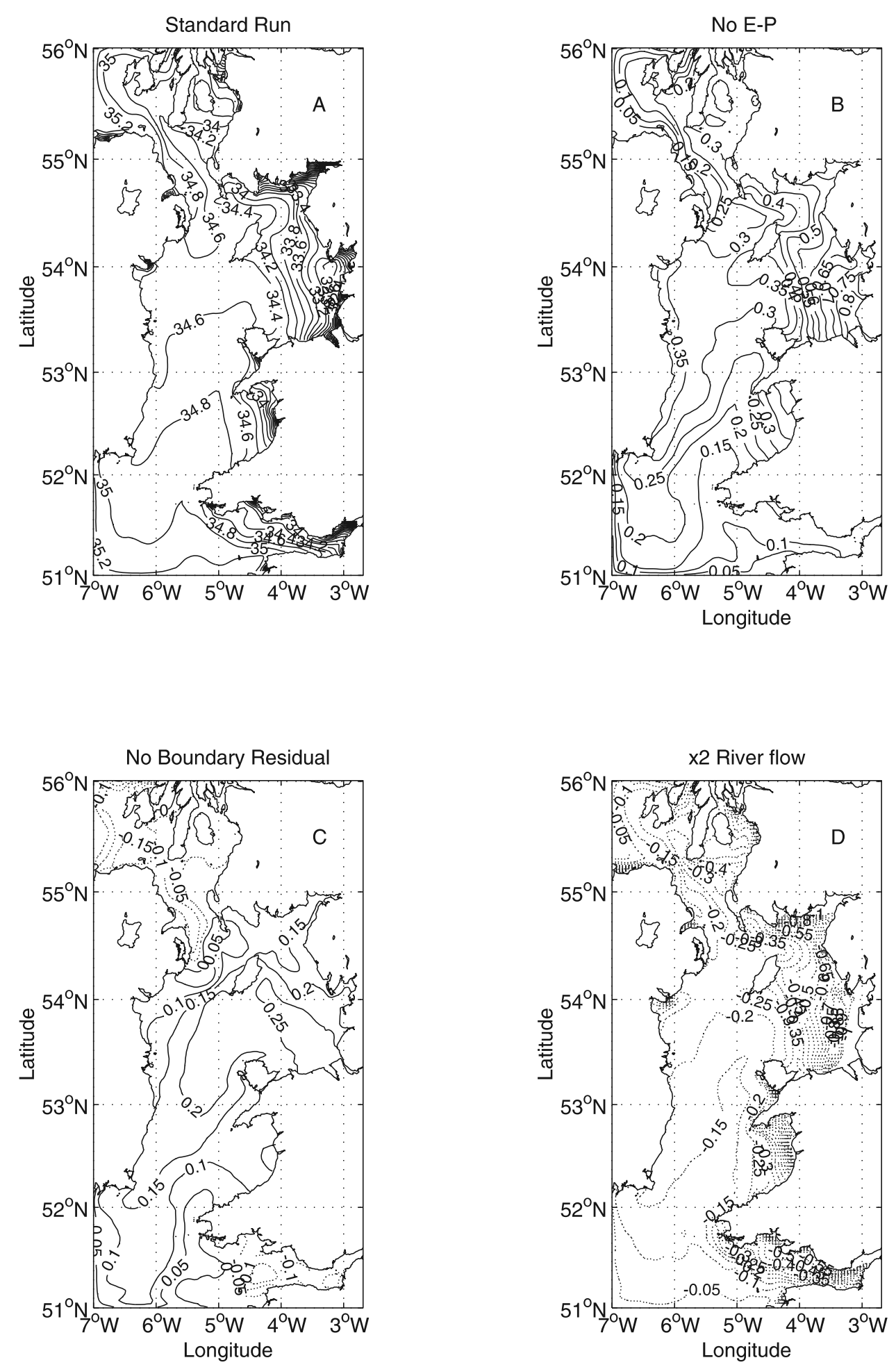

Figure 9. Surface salinity (psu) average for 1980-1989 for (a) standard model run, (b) run without surface salinity fluxes, (c) run without boundary residual currents and elevations, and (d) run with $\times 2$ river inflows.

[26] The method used to prescribe riverine inputs to the model, described in section 2, provides good estimates of the river flux for the temporal periods when gauged river data exists, but errors are introduced by the substitution of an annual average cycle when data are unavailable, as interannual variability is then neglected. Simulations using only the average annual cycles (not described here) found the observed salinity at Cypris station is very poorly reproduced. Hence the inclusion of the interannual variability in river flows has a very significant influence on model results. Results from the simulation with increased river inflow allow us to demonstrate the extra fresh water flux 
needed to achieve a more accurate absolute salinity. Doubling the river inflows (Figure 9d) reduces the salinity by on average 0.32 psu overall and $\sim 1.0 \mathrm{psu}$ in the eastern Irish Sea. This is sufficient to account for over prediction of salinities at Cypris station by on average $0.3 \mathrm{psu}$, but not the mean difference seen in the CTD comparison (Table 1). Hence accuracy of the river forcing is unlikely to be the main source of error.

[27] Considering now model experiment 2 with no boundary residual elevations and currents, the results presented in Table 3 demonstrate that the salinity (anomaly) flux makes a substantial contribution to the salinity variability in the central (region C) and eastern (region A) Irish Sea. As demonstrated by these calculations the residual transport through the Irish Sea region is northward, thus water entering the Irish Sea generally originates from the Celtic Sea (although storms can occasionally push water from the North Channel as far south as Cypris Station). When boundary residual forcing is not imposed on the model the volume transport through Irish Sea for 19601961 (Table 3) is approximately doubled (although still within the observed range [e.g., Brown and Gmitrowicz, $1995])$. This results in a small $(\sim 5 \%)$ increase in the anomaly flux into the eastern Irish Sea, but a fractionally large increase in the tendency term $(d \bar{S} / d t ; \sim 30 \%)$. This experiment (Figure 9c) shows a general increase in salinity throughout the domain and demonstrates a significant sensitivity of the salinity to the volume flux through the Irish Sea, especially in shallow regions (small $V$ in equation (1)). The anomaly flux in the eastern Irish Sea needs only to be reduced by $\sim 13 \%$ to eliminate the tendency term here.

[28] The increase in volume transport in experiment 2 can be explained by the south to north sea level gradient imposed by the boundary condition. This tends to counteract the locally forced northward residual flow, so removing the residual boundary conditions will enhance this flow. Proctor [1981] noted that the local northward forcing within the Irish Sea ought to produce a substantially greater volume flux than that observed and that this could be accounted for by a counteracting large-scale pressure gradient. This can also be seen in the North Channel as a reduction in the intrusion of saline water on the Irish side in Figure 9c. The mean south-north sea level difference in the boundary condition data for the $1980 \mathrm{~s}$ is $0.05 \mathrm{~m}$. This is less than the typically observed mean sea level difference across the model domain; a $\sim 0.10 \mathrm{~m}$ drop from Islay (north of the northern boundary) to Newlyn (south of the southern model boundary (D. Blackman, POL, personal communication, 2005). Hence it is distinctly possible that the overestimation of salinity in this model is caused by an underestimation of the north-south sea level gradient and consequent enhanced flux through the Irish Sea. In turn this is likely to result from using boundary condition data from a two-dimensional model that excludes any density effects on sea level.

[29] A time series of observations for the period 19601987 from a location in the Celtic Sea, just off the southwest tip of England $\left(6.067^{\circ} \mathrm{W}, 50.067^{\circ} \mathrm{N}\right)$ can be used to assess the extent to which variability in salinity in the Celtic Sea affects that at Cypris station, and hence the likely sensitivity of the central Irish Sea salinities to the boundary values. The observed salinity variability at this site is compared with that observed at Cypris station, including consideration of the transport time between the two sites. For the range of temporal lags considered (up to 100 days), the maximum correlation is only 0.17 , suggesting the salinity variability at Cypris station is not correlated with that in the Celtic Sea. Moreover the absolute variability measured in the Celtic Sea is substantially less than that at Cypris Station; the overall standard deviation is $0.13 \mathrm{psu}$ compared with $0.24 \mathrm{psu}$ at Cypris. Hence upstream variation in salinity cannot account for the variability at Cypris station but, as shown, variations in salinity flux through the Irish Sea can.

[30] These results show that, while the model is able to reproduce some of the trends in salinity variability over the 40 year period, it does not simulate the absolute values of salinity to the accuracy obtained for temperature. Largerscale variability and volume flux have a greater influence on salinity than temperature (which is strongly constrained by atmospheric forcing) within the Irish Sea, and at present these are not represented with sufficient accuracy in this model. The comparisons with CTD data and the sensitivity experiments suggest a discrepancy of this size could be due to boundary conditions, surface and/or riverine forcing, but of these we have least confidence in our representation of the boundary conditions.

\section{Variability in Temperature Stratification}

[31] The seasonal development of stratification in the western Irish Sea is shown in Figure 10 for 1995. This particular year is chosen because it coincides with a number of surveys of this region [Horsburgh et al., 2000]. Temperature stratification is represented here by the surface to bed temperature difference, $T_{\mathrm{d}}$; Figure 10 shows fortnightly averages of $T_{\mathrm{d}}$, starting shortly after the onset of seasonal stratification (defined by a maximum $T_{\mathrm{d}}$ in the western Irish Sea consistently exceeding $1^{\circ} \mathrm{C}$ ) on approximately 5 April 1995. Stratification in 1995 breaks down on approximately 2 October (defined by a maximum $T_{\mathrm{d}}$ in the western Irish Sea consistently below $1^{\circ} \mathrm{C}$ ). Throughout this period stratification is strongest to the southwest of the Isle of Man, with the location of peak $T_{\mathrm{d}}$ being nearly constant, varying by $\sim 0.2^{\circ}$ longitude and $\sim 0.4^{\circ}$ latitude. Starting from a patch to the southwest of the Isle of Man, the stratified region gradually extends northward to the North Channel with a persistent weak $T_{\mathrm{d}}$ predicted in the North Channel from the end of May to the end of August. Strong stratification is unable to develop here because of the large tidal currents. From late May a tongue of strong stratification develops extending northward to the west of the Isle of Man following the orientation of the deep channel (Figure 1). Weak stratification gradually extends southward toward St George's Channel but is sufficiently weak for the frontal systems associated with the density structures in the Irish and Celtic Seas to remain distinct. The model shows the region of strongest stratification remains constrained to the deep, weak tidal region of the western Irish Sea. Stratification starts to break down at the end of August and has disappeared from the western Irish Sea by October.

[32] This modeled seasonal cycle of stratification agrees well with the observations described by Horsburgh et al. [2000]. The maximum model $T_{\mathrm{d}}$ of $6.6^{\circ} \mathrm{C}$, on $21 \mathrm{July}$, is in good agreement, and at an approximately coincident location, with the observed maximum of $6.7^{\circ} \mathrm{C}$ on 24 July. Both 

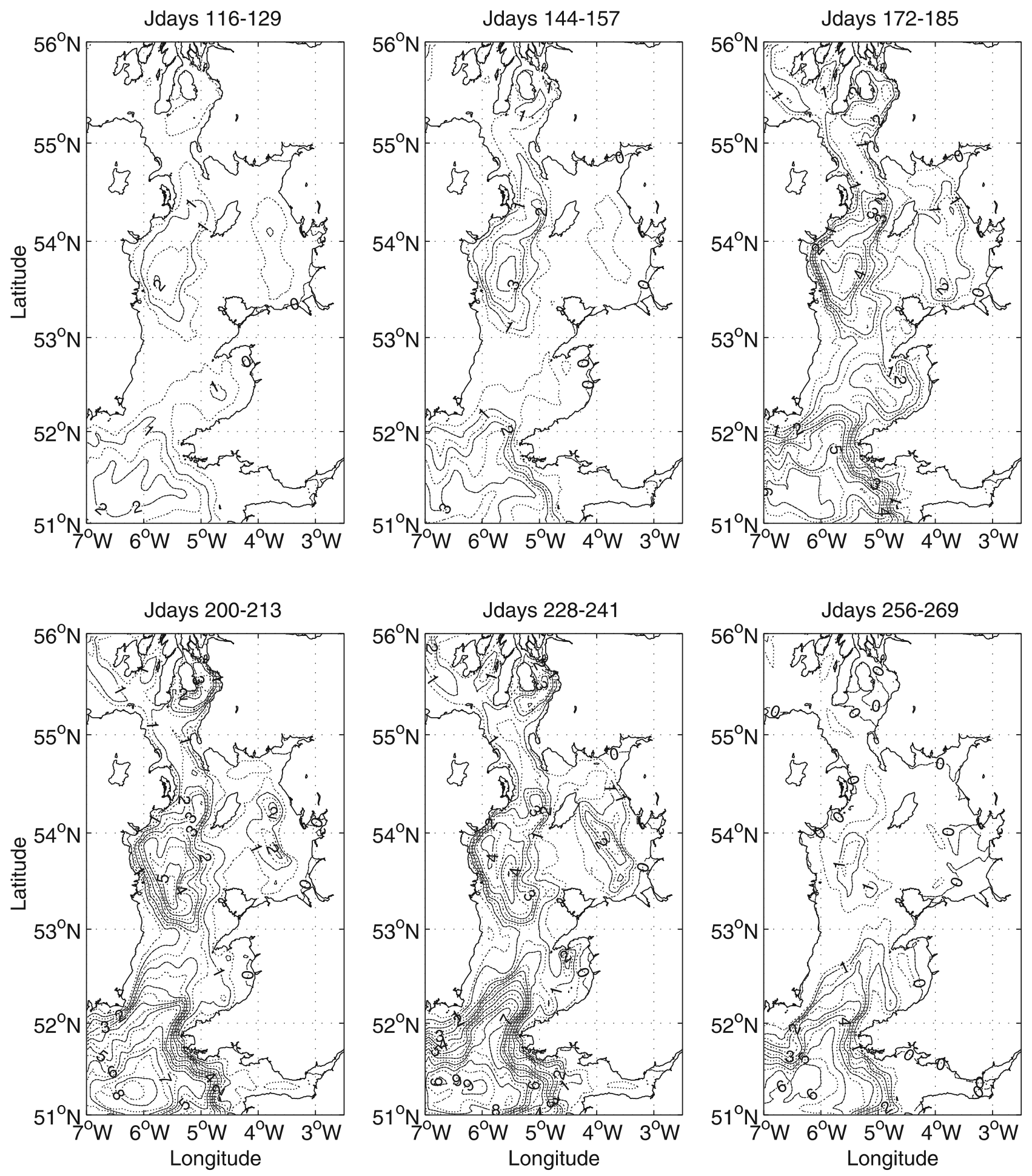

Figure 10. Seasonal development of stratification in the Irish Sea in 1995, expressed as average surface to bed temperature difference.

the distribution and strength of stratification are reproduced throughout July and August, and the timing of the breakdown and gradual reduction in geographical extent of stratification agree well with the observations.

[33] Figure 11 shows how the timing of the stratification cycle varies throughout the 40 year simulation period. Over this time, the onset of stratification varied by up to a month (but without obvious trend), from 31 March in 1991 (Jday 90) to 30 April in 1966 (Jday 120), with an average start date of 16 April. The geographical pattern of stratification is essentially the same from year to year with a maximum $T_{\mathrm{d}}$ to the southwest of the Isle of Man, extending northward following the deep bathymetry. Only minor differences in the maximum extent of the stratification are produced, as 


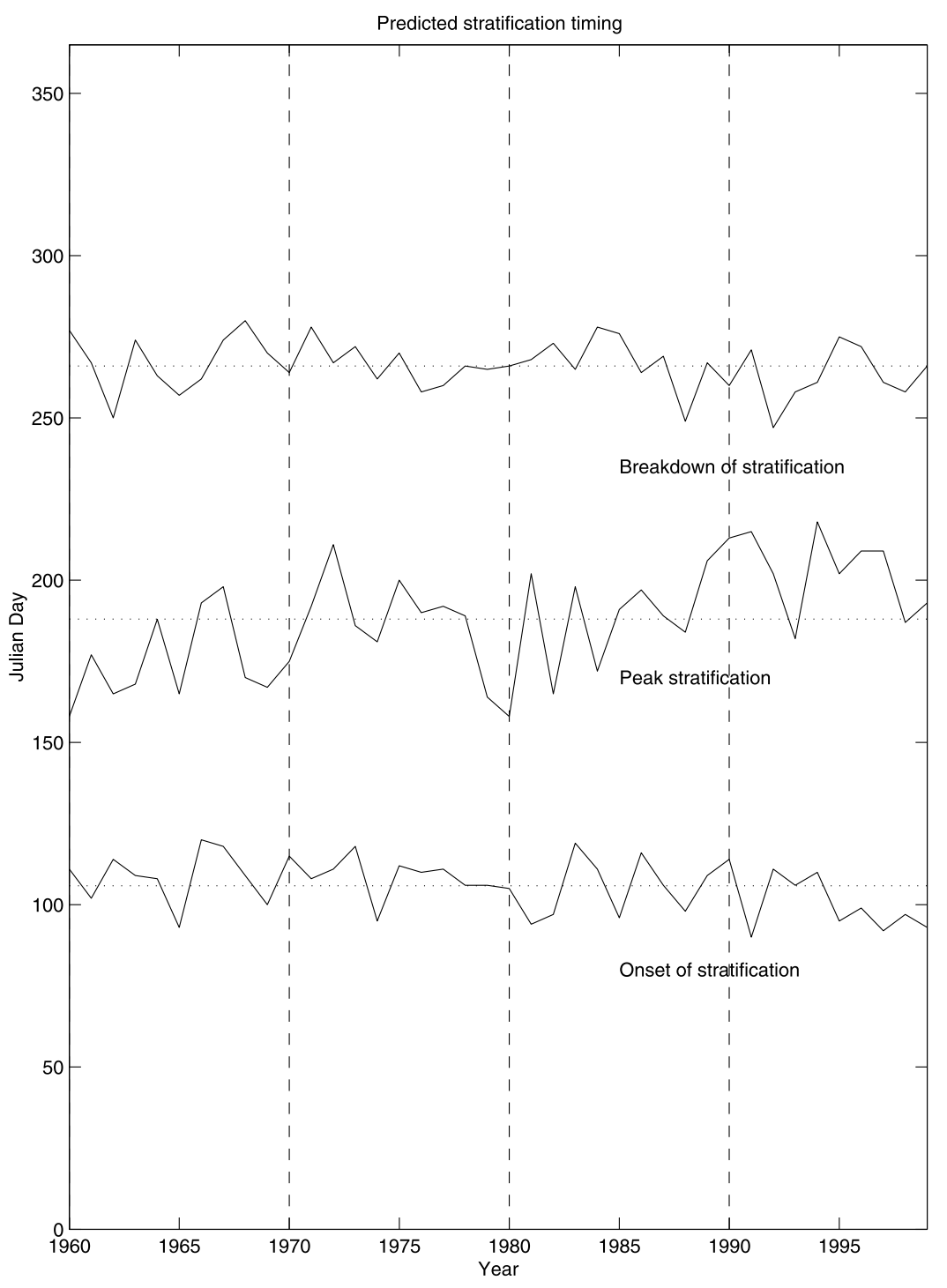

Figure 11. Modeled variability in the timings of the onset, peak, and breakdown of stratification in the western Irish Sea over the period 1960-1999.

illustrated for the years 1981 and 1995 in Figure 12. Here 21 July (Jday 202) was the date with maximum $T_{\mathrm{d}}$ in both years. It can be seen that although there is significantly stronger stratification predicted in 1995, the geographical extent of stratification has not changed significantly, with just minor extensions of weak $T_{\mathrm{d}}$ to the east and south of the central stratified region. The timing of peak stratification varies by nearly two months, from 7 June in 1980 (Jday 158) to 6 August in 1994 (Jday 218) (Figure 11), with an average date of 8 July, but with a definite trend for the peak stratification to be delayed over the course of these 40 years. The peak surface to bed temperature difference has a mean value of $5.31^{\circ} \mathrm{C}$ with a range of over $3^{\circ} \mathrm{C}$; a minimum of $3.56^{\circ} \mathrm{C}$ occurs in 1962 and a maximum of $6.83^{\circ} \mathrm{C}$ in 1983 . The breakdown of stratification ranged from 4 September in 1992 (Jday 247) to 7 October in 1968 (Jday 280) (Figure 11), with an average date of 23 September. These results suggest that while the location and extent of stratification in the western Irish Sea is fixed by bathymetry and tidal currents, there is a high degree of interannual variabil- ity in the timing and strength of stratification, dependent on the variability in atmospheric forcing.

\section{Summary}

[34] This paper describes the application of a fineresolution, regional-scale model to the simulation of decadal variability of temperature and salinity in the Irish Sea. Unlike many other such simulations this model is run without relaxation to seasonal climatology and so gives an accurate account of the model's response to the forcing. One of the foci of this work is accurately representing the salinity forcing, an area neglected in previous studies on the northwest European Shelf. Comparisons with 3397 CTD profiles over the 40 year simulation period (1960-1999) show temperatures to be modeled to a high degree of accuracy, with mean and RMS errors of $-0.01^{\circ} \mathrm{C}$ and $0.78^{\circ} \mathrm{C}$ respectively with little drift or obvious spatial variation. Modeled temperature variability also agrees well with long-term observations at Cypris station, a site to the 

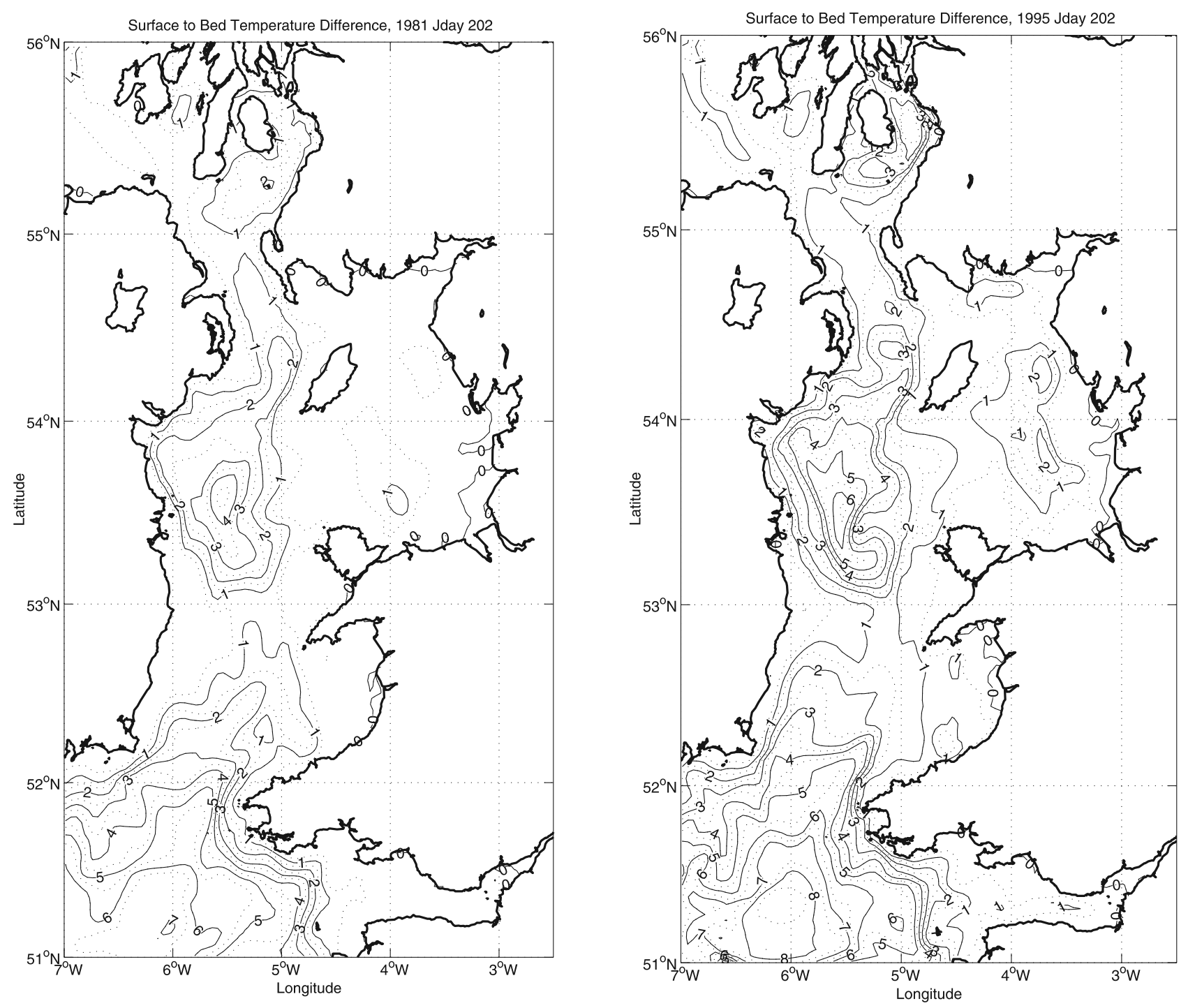

Figure 12. Comparison of surface to bed temperature difference in 1981 and 1995 on the days when stratification in the western Irish Sea was a maximum.

southwest of the Isle of Man. These results show the summer temperatures in the whole Irish Sea to be warming at a rate of $\sim 0.01^{\circ} \mathrm{C} \mathrm{yr}^{-1}$, and the fact that warming at this rate is also observed in the Cypris station time series lends weight to this conclusion.

[35] Salinities are less well reproduced by the model, being consistently too high after a period of approximately the flushing time of the Irish sea has elapsed. Comparisons with CTD data yield mean and RMS values of 0.79 psu and 0.98 psu respectively, with salinities consistently overestimated. The regions with the largest errors are the Bristol Channel, the eastern Irish Sea and around the Scottish islands, in particular the Clyde Sea. A number of sensitivity studies have been conducted and these suggest that the large-scale error in absolute salinity is most likely to result from the boundary condition's mean sea level effects on the volume flux through the Irish Sea. There may also be a contribution from the surface forcing, but this is likely to be overestimating the precipitation (being derived from landbased measurements). Comparisons with the time series of salinity from Cypris station also showed that the model is generally too saline, but it has some skill in representing salinity variability with periods up to 2 years. However, it fails to predict the decadal-scale variability (which is seen here to be of similar magnitude to the seasonal variability), the cause of which has yet to be definitively established.

[36] Model estimates of the seasonal development and breakdown of stratification in the western Irish Sea in 1995 agree well with an extensive data set presented by Horsburgh et al. [2000]. Strongest stratification occurs in a region to the southwest of the Isle of Man, with stratification confined to a region of weak tides and deep bathymetry in the western Irish Sea, as suggested by theory [Simpson and Hunter, 1974]. Over the 40 year simulation period, the geographical distribution of stratification in the western Irish Sea varies little. However, there is significant variability in the timing of stratification, with the onset and breakdown varying by up to a month. The date of peak stratification varies by up to two months and shows a significant trend to occur later in the year. In addition, the 
maximum surface to bed temperature difference ranged from $3.56^{\circ} \mathrm{C}$ in 1962 to $6.83^{\circ} \mathrm{C}$ in 1983 . The fronts associated with the stratification in the western Irish Sea form a cyclonic gyre. This provides a physical mechanism whereby the pelagic larvae of the commercially valuable Norway lobster, Nephrops norvegicus, are retained close to the muddy substrate they require for settlement [Hill et al., 1996]. Variability in the timing of the onset of stratification in relation to spawning, and the subsequent strength of the flows associated with the bottom density fronts, could affect the retention and recruitment of the larvae.

[37] In this paper we have demonstrated the value of a regional model with limited boundary conditions in furthering our understanding of long-term change in shelf seas. While a number of shortcomings of this approach have been demonstrated, the application of the model to the study of long-term warming and the interannual variability in stratification has clearly demonstrated its value. Coupled hydrodynamic-ecosystem models have become an important tool for the investigation of shelf sea processes, but are usually employed on seasonal timescales. However, many of these processes act on annual to decadal timescales (e.g., nutrient transport, benthic cycling, ecosystem response to climate change) requiring increasingly long integration times. Knowledge of the relative importance of boundary influences then becomes crucial to keeping the problem tractable. Since this study was conducted new atmospheric model data sets have become available (particularly ERA40, see www.ecmwf.int/research/era/), and since we have demonstrated the region to be strongly determined by the atmospheric forcing, investigating the sensitivity to the details of the meteorological forcing would be an obvious next step.

[38] Acknowledgments. This work was partially supported by NERC grant NER/A/S/2001/00559. The bathymetry used for this work was funded by the Department of Transport and the Regions and the Ministry of Agriculture Fisheries and Food [Brown et al., 1999]. AVHRR data were obtained from the NASA Physical Oceanography Distributed Active Archive Center at the Jet Propulsion Laboratory, California Institute of Technology. NCEP reanalysis data were provided by the NOAA-CIRES Climate Diagnostics Center, Boulder, Colorado, United States, from their Web site at http://www.cdc.noaa.gov/. High-resolution CTD data were provided by the British Oceanographic Data Centre (BODC), and lowresolution data were obtained from the International Council for the Exploration of the Seas (ICES). Time series analysis of salinity data was performed by Simon Williams (POL). We would like to thank Roger Proctor (POL) for his useful comments on the text. The detailed comments of two anonymous referees are also appreciated.

\section{References}

Arakawa, A. (1972), Design of the UCLA general circulation model, Tech. Rep. 7, Univ. of Calif., Los Angeles.

Bell, M. J., R. M. Forbes, and A. Hines (2000), Assessment of the FOAM global data assimilation system for real time operational ocean forecasting, J. Mar. Syst., 25, 1-22.

Bowden, K. F. (1980), Physical and dynamical oceanography of the Irish Sea, in The North-West European Shelf Seas: The Sea Bed and the Sea in Motion, vol. 2, Physical and Chemical Oceanography, and Physical Resources, Elsevier Oceanogr. Ser., vol. 24B, edited by F. T. Banner, M. B. Collins, and K. S. Massie, pp. 391-413, Elsevier, New York.

Brown, J., and E. M. Gmitrowicz (1995), Observations of the transverse structure and dynamics of the low frequency flow through the North Channel of the Irish Sea, Cont. Shelf Res., 15, 1133-1156.

Brown, J., A. E. Joyce, J. N. Aldridge, E. F. Young, L. Fernand, and P. A. Gurbutt (1999), Further identification and acquisition of bathymetric data for Irish Sea modeling, DETR Res. Contract CW0753, Dep. for Environ., Transport, and the Regions, London.

Copplestone, D., D. Jackson, R. G. Hartnoll, M. S. Johnson, P. McDonald, and N. Wood (2004), Seasonal variations in activity concentrations of
${ }^{99} \mathrm{Tc}$ and ${ }^{137} \mathrm{Cs}$ in the edible meat fraction of crabs and lobsters from the central Irish Sea, J. Environ. Radioactiv., 73, 29-48.

Czitrom, S. P. R. (1986), The effect of river discharge on the residual circulation in the eastern Irish Sea, Cont. Shelf Res., 6, 475-485.

Evans, G. L., P. J. le B. Williams, and E. G. Mitchelson-Jacob (2003), Physical and anthropogenic effects on observed long-term nutrient changes in the Irish Sea, Estuarine Coastal Shelf Sci., 57, 1159-1168.

Flather, R. A., R. Proctor, and J. Wolf (1991), Oceanographic forecast models, in Computer Modelling in the Environmental Sciences, IMA Conf. Ser., vol. 28, edited by D. G. Farmer and M. J. Rycroft, pp. 1530, Clarendon, Oxford, U. K.

Gill, A. E. (1982), Atmosphere-Ocean Dynamics, 662 pp., Elsevier, New York.

Gowen, R. J., D. K. Mills, M. Trimmer, and D. B. Nedwell (2000), Production and its fate in two coastal regions of the Irish Sea: The influence of anthropogenic nutrients, Mar. Ecol. Prog. Ser, 208, 51-64.

Heaps, N. S. (1972), Estimation of density currents in the Liverpool Bay area of the Irish Sea, Geophys. J. R. Astron. Soc., 30, 415-432.

Hill, A. E., J. Brown, and L. Fernand (1996), The western Irish Sea gyre: A retention mechanism for the Norway lobster (Nephrops norvegicus)?, Oceanol. Acta, 19, 357-368.

Holt, J. T., and I. D. James (2001), An $s$ coordinate density evolving model of the northwest European continental shelf: 1. Model description and density structure, J. Geophys. Res., 106(C7), 14,015-14,034.

Holt, J. T., and R. Proctor (2003), The role of advection in determining the temperature structure of the Irish Sea, J. Phys. Oceanogr., 33, 22882306 .

Holt, J. T., I. D. James, and J. E. Jones (2001), An $s$ coordinate density evolving model of the northwest European continental shelf: 2. Seasonal currents and tides, J. Geophys. Res., 106(C7), 14,035-14,053.

Horsburgh, K. J., A. E. Hill, and J. Brown (1998), A summer jet in the St. George's Channel of the Irish Sea, Estuarine Coastal Shelf Sci., 47, $285-294$.

Horsburgh, K. J., A. E. Hill, J. Brown, L. Fernand, R. W. Garvine, and M. M. P. Angelico (2000), Seasonal evolution of the cold pool gyre in the western Irish Sea, Prog. Oceanogr., 46, 1-58.

Howarth, M. J. (1982), Non-tidal flow in the North Channel of the Irish Sea, in Hydrodynamics of Semi-Enclosed Shelf Seas, edited by J. C. J. Nihoul, pp. 205-241, Elsevier, New York.

Intergovernmental Panel for Climate Change (2001), Climate Change 2001: The Scientific Basis. Contributions of Working Group I to the Third Assessment Report of the Intergovernmental Panel on Climate Change, edited by J. T. Houghton et al., 881 pp., Cambridge Univ. Press, New York.

James, I. D. (1996), Advection schemes for shelf sea models, J. Mar. Syst., $8,237-254$.

Jones, P. G. W., and A. R. Folkard (1971), Hydrographic observations in the eastern Irish Sea with particular reference to the distribution of nutrient salts, J. Mar. Biol. Assoc. U. K., 51, 159-182.

Kalnay, E., et al. (1996), The NCEP/NCAR 40-year reanalysis project, Bull. Am. Meteorol. Soc., 77(3), 437-471.

Knight, P. J., and M. J. Howarth (1999), The flow through the North Channel of the Irish Sea, Cont. Shelf Res., 19, 693-716.

Leonard, K. S., D. McCubbin, J. Brown, R. Bonfield, and T. Brooks (1997), Distribution of technetium-99 in UK coastal waters, Mar. Pollut. Bull., $34,628-636$

Luyten, P. J., J. E. Jones, R. Proctor, A. Tabor, P. Tett, and K. Wild-Allen (1999), COHERENS - A coupled hydrodynamical-ecological model for regional and shelf seas: User documentation, report, 914 pp., Manage. Unit of the Math. Models of the North Sea, Brussels.

Marsh, T. J., and F. J. Sanderson (2003), Derivation of daily outflows from hydrometric areas, report, 14 pp., Proudman Oceanogr. Lab., Natl. River Flow Arch., Cent. for Ecol. and Hydrol., Wallingford, U.K., July.

Pingree, R. D., and D. K. Griffiths (1980), Currents driven by a steady uniform wind stress on the shelf seas around the British Isles, Oceanol. Acta, 3, 227-236.

Proctor, R. (1981), Tides and residual circulation in the Irish Sea: A numerical modelling approach, Ph.D. thesis, Liverpool Univ., Liverpool, U. K.

Proctor, R., and I. D. James (1996), A fine-resolution 3D model of the southern North Sea, J. Mar. Syst., 8, 285-295.

Sharples, J., and J. H. Simpson (1995), Semi-diurnal and longer period stability cycles in the Liverpool Bay region of freshwater influence, Cont. Shelf Res., 15, 295-313.

Sheppard, C. (2004), Sea surface temperature 1871-2099 in 14 cells around the United Kingdom, Mar. Pollut. Bull., 49, 12-16.

Simpson, J. H. (1971), Density stratification and microstructure in the western Irish Sea, Deep Sea Res. Oceanogr. Abstr., 18(3), 309-319.

Simpson, J. H., and J. R. Hunter (1974), Fronts in the Irish Sea, Nature, $250,404-406$. 
Visser, M., et al. (1996), Time series analysis of monthly mean data of temperature, salinity, nutrients suspended matter, phyto- and zooplankton at eight locations on the northwest European shelf, Dtsch. Hydrogr. Z., 48, 299-323.

Young, E. F., J. N. Aldridge, and J. Brown (2000), Development and validation of a three-dimensional curvilinear model for the study of fluxes through the North Channel of the Irish Sea, Cont. Shelf Res., 20, $997-$ 1035.

Young, E. F., J. Brown, and J. N. Aldridge (2001), Application of a large area curvilinear model to the study of the wind-forced dynamics of flows through the North Channel of the Irish Sea, Cont. Shelf Res., 21, 1403 1434.

J. T. Holt, Proudman Oceanographic Laboratory, Joseph Proudman Building, 6 Brownlow Street, Liverpool L3 5DA, UK. (jholt@pol.ac.uk)

E. F. Young, British Antarctic Survey, High Cross, Madingley Road, Cambridge CB3 0ET, UK. 